\title{
Ortho-Hydroxylative ipso-Cyclization of $\mathrm{N}$-arylpropiolamide
}

Yu-Chao Wang, ${ }^{\dagger}$ Jin-Biao Liu, ${ }^{*}{ }^{\dagger}$ Hongwei Zhou, ${ }^{\star}$ Wenlin Xie,${ }^{\S}$ Pornchai

Rojsitthisak, ${ }^{\mathbb{I}}$ and Guanyinsheng Qiu*,\$,

${ }^{\dagger}$ School of Metallurgical and Chemical Engineering, Jiangxi University of Science and Technology, 86

Hongqi Road, Ganzhou 341000, China

${ }^{\sharp}$ College of Biological, Chemical Sciences and Engineering, Jiaxing University, Jiaxing 314001,

Zhejiang, China

${ }^{\S}$ School of Chemistry and Chemical Engineering, Hunan University of Science and Technology,

Hunan 411201, China

${ }^{\pi}$ Department of Food and Pharmaceutical Chemistry, Faculty of Pharmaceutical Sciences,

Chulalongkorn University, 254 Phayathai Road, Patumwan, Bangkok 10330, Thailand 
1. Crystallographic Data for Compound 4a and 5e

S3 - S6

2. Structure of Compound 1, 4, 5, 6 and 7

S7 - S9

3. NMR Spectra for Compounds 1, 4, 5, 6 and 7

S10 - S49 
X-ray Crystal structure and crystal data of compound 4a (CCDC: 1949294)

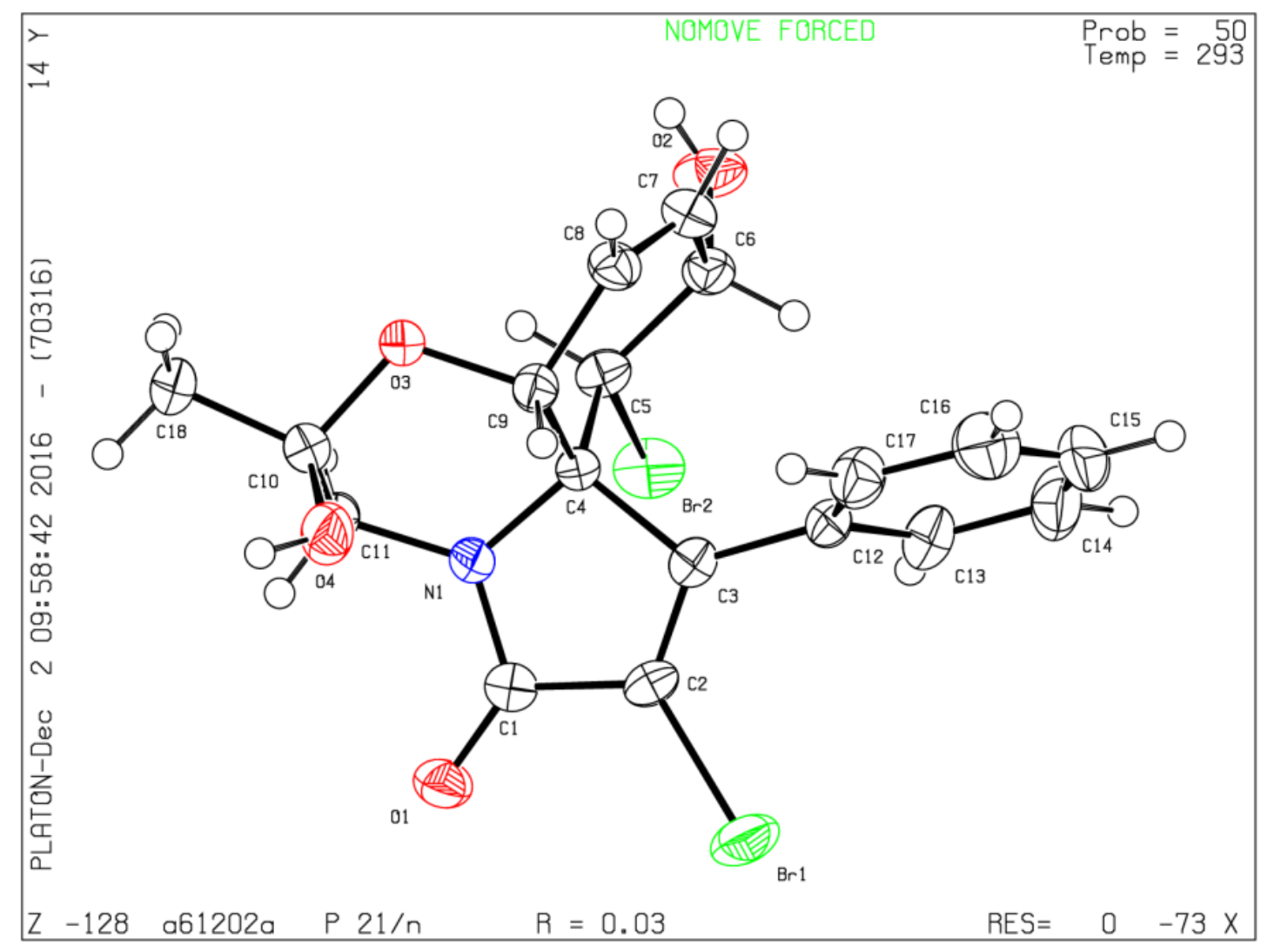

Figure S1. Molecular structure of compound 4a shown with 50\% ellipsoidal probability. 
Table S1: Crystal data and structure refinement for compound 4a

The compound $4 \mathbf{a}$ was crystallized from $\mathrm{CH}_{2} \mathrm{Cl}_{2} / \mathrm{PE}$ mixture at room temperature.

\section{Compound $4 a$}

\section{Datablock: a61202a}

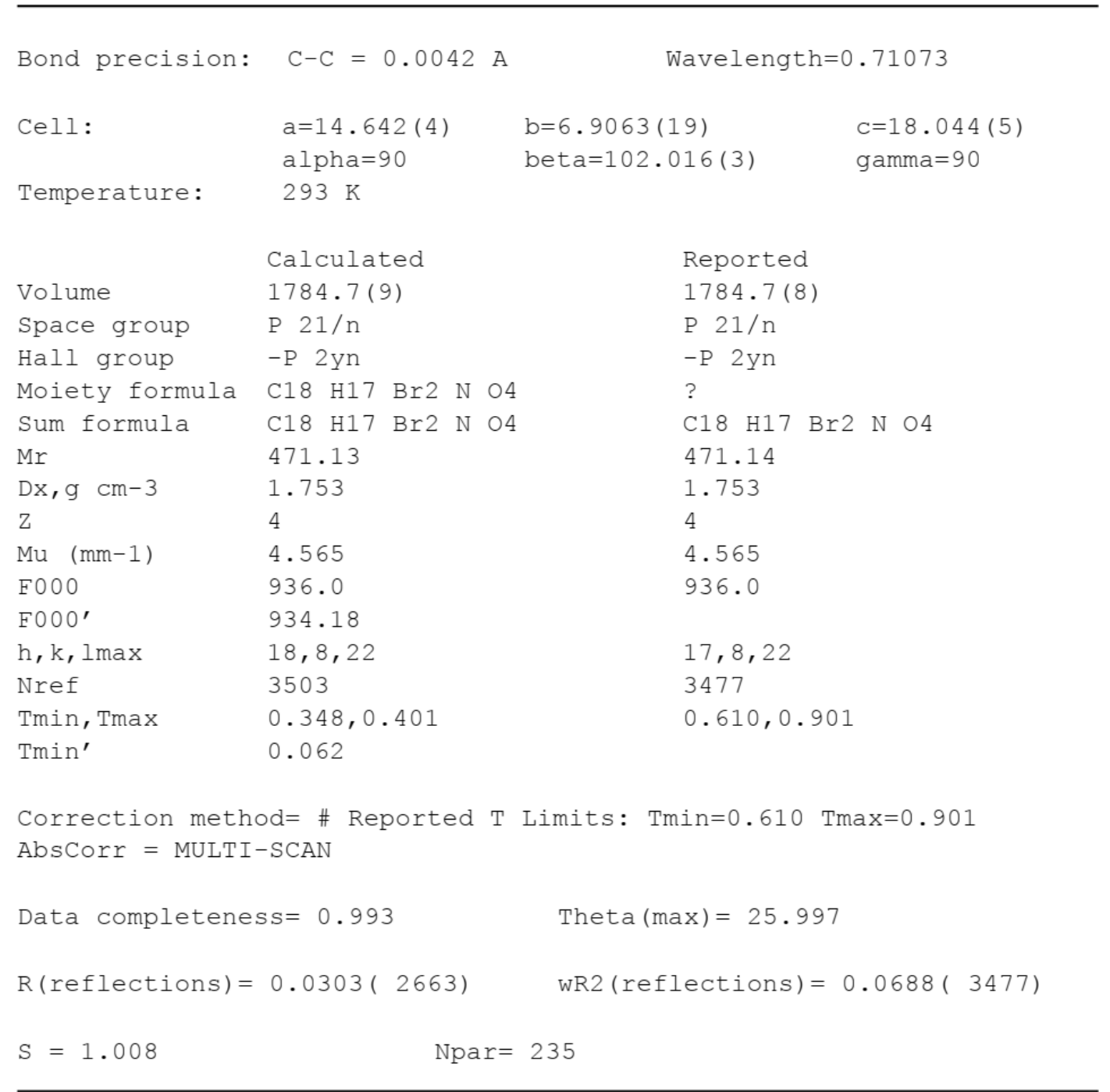


X-ray Crystal structure and crystal data of compound 5e (CCDC: 1949293)

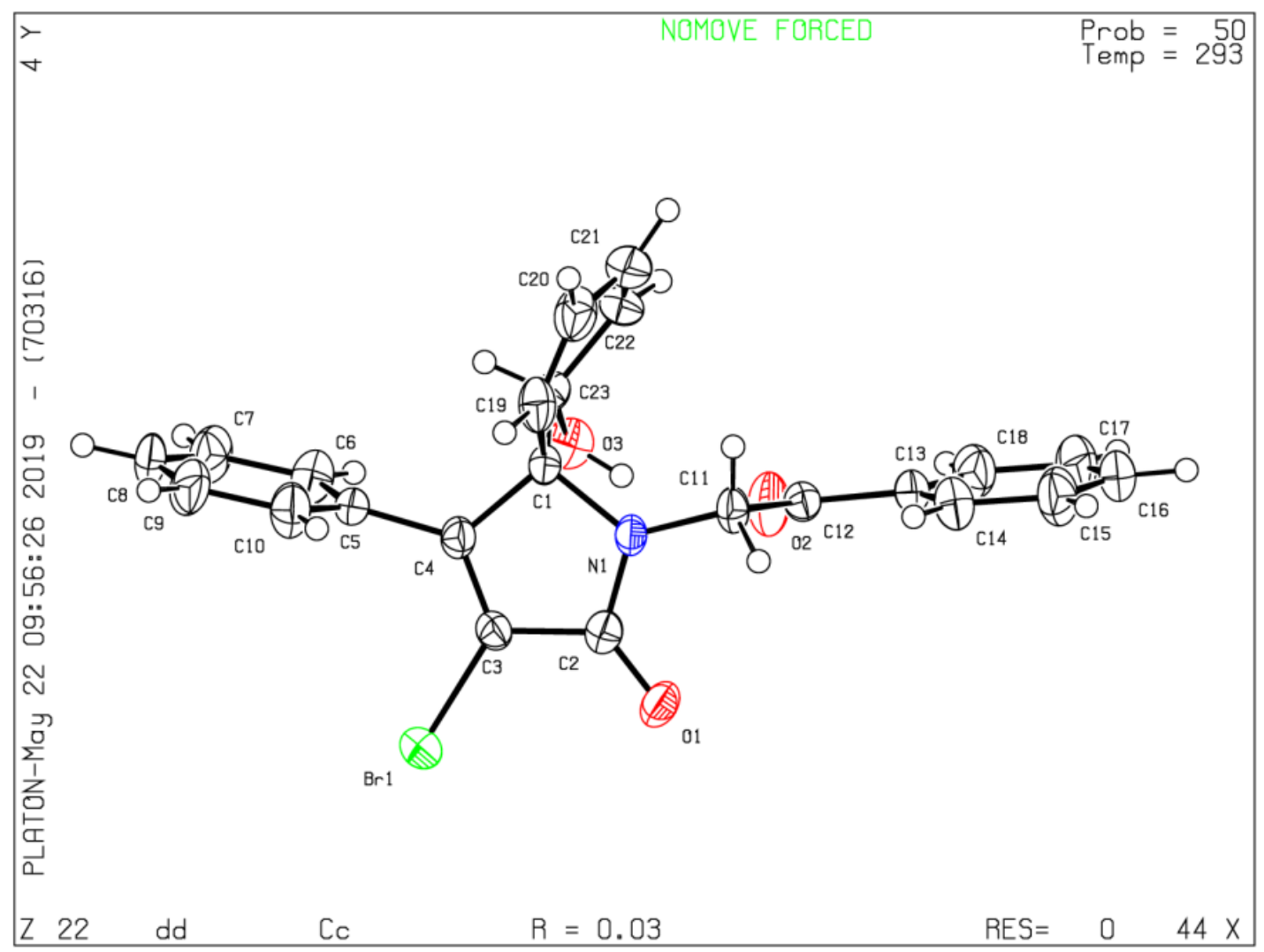

Figure S2. Molecular structure of compound 5e shown with 50\% ellipsoidal probability. 
Table S2: Crystal data and structure refinement for compound 5e

The compound $\mathbf{5 e}$ was crystallized from $\mathrm{CH}_{2} \mathrm{Cl}_{2} / \mathrm{PE}$ mixture at room temperature.

\section{Compound 5e}

\section{Datablock: dd}

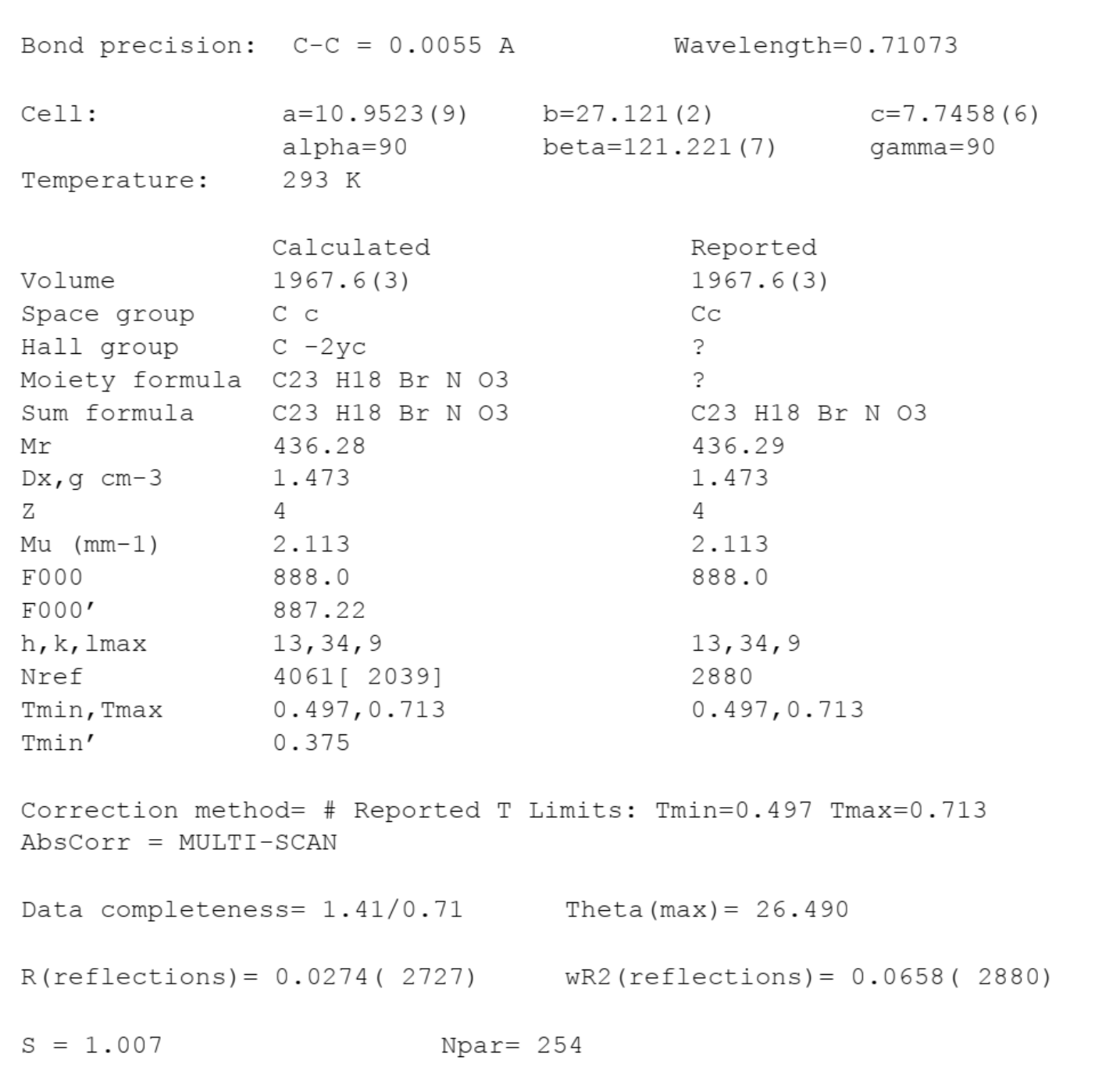


Structure of starting compound (1a-m, 1p-t):

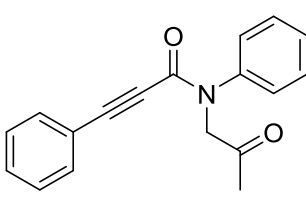

1a<smiles>O=C(CN(C(=O)C#Cc1ccccc1)c1ccccc1)c1ccccc1</smiles><smiles>Cc1ccc(C(=O)CN(C(=O)C#Cc2ccccc2)c2ccccc2)cc1</smiles><smiles>COc1ccc(C#CC(=O)N(CC(C)=O)c2ccccc2)cc1</smiles>

1b<smiles>O=C(CN(C(=O)C#Cc1ccccc1)c1ccccc1)C1CC1</smiles><smiles>CC(=O)CN(C(=O)C#Cc1ccc(C)cc1)c1ccccc1</smiles>

1j $1 \mathrm{i}$<smiles>CC(=O)CN(C(=O)C#Cc1ccccc1)c1ccc(C#Cc2ccccc2)cc1</smiles>

$1 p$<smiles>CC(=O)CN(C(=O)C#Cc1ccccc1)c1ccccc1</smiles>

1d<smiles>COc1ccc(C(=O)CN(C(=O)C#Cc2ccccc2)c2ccccc2)cc1</smiles><smiles>CC(=O)CN(C(=O)C#Cc1cccc2ccccc12)c1ccccc1</smiles><smiles>CC(=O)CN(C(=O)C#Cc1ccccc1)c1ccc(-c2ccccc2)cc1</smiles><smiles>CC(=O)CN(C(=O)C#Cc1ccccc1)c1ccc(C)cc1</smiles>

1s

Figure S3. Structure of compound 1. 
Structure of compound (4a-g):<smiles>CC1(O)CN2C(=O)C(Br)=C(Br)C23C(O)C=CC(O)C3O1</smiles>

$4 a$<smiles>CC(O)(O)CN1C(=O)C(Br)=C(c2ccccc2)C12C=CC(F)=CC2O</smiles><smiles>CC1(O)CN2C(=O)C(Br)=C(Br)C23C(C=C(c2ccccc2)C(O)C3Br)O1</smiles>

4b<smiles>CC(=O)CN1C(=O)C(Br)=C(c2ccccc2)C12C=CC(=O)C=C2</smiles><smiles>CC1(O)CN2C(=O)C(Br)=C(Br)C2(C(Br)c2ccccc2)C2C=C(Cl)C(O)C(C2)O1</smiles>

4c<smiles>C=C1C=CC2(C=C1)C(c1ccccc1)=C(Br)C(=O)N2CC(C)=O</smiles><smiles>Cc1ccccc1C1=C(Br)C(=O)N2CC(C)(O)OC3C=CC(O)C(Br)C132</smiles>

4d

Figure S4. Structure of compound 4.

\section{Structure of compound (5a-n):}<smiles>CC(=O)CN1C(=O)C(Br)=C(c2ccccc2)C12C=CC=CC2O</smiles>

$5 a$<smiles></smiles><smiles>CC(=O)CN1C(=O)C(Br)=C(c2cccs2)C12CC=CCC2O</smiles>

$5 k$<smiles>O=C(CC1C(O)C=CCC12C(=O)C(Br)=C2c1ccccc1)C1CC1</smiles>

5b<smiles>CCCCOc1ccc(C(=O)CN2C(=O)C(Br)=C(c3ccccc3)C23CC=CCC3O)cc1</smiles><smiles>CC(=O)CN1C(=O)C(Br)=C(c2cccc3ccccc23)C12CC=CCC2O</smiles>

5<smiles>CCC(=O)CN1C(=O)C(Br)=C(c2ccccc2)C12CC=CCC2O</smiles>

$5 c$<smiles>O=C(CN1C(=O)C(Br)=C(c2ccccc2)C12CC=CCC2O)c1ccc2ccccc2c1</smiles><smiles>COc1ccc(C2=C(Br)C(=O)N(CC(C)=O)C23CC=CC=C3O)cc1</smiles><smiles>CC(=O)CN1C(=O)C(Br)=C(c2ccccc2)C12CC1=CC(C#Cc3ccccc3)=CC(O)C12</smiles>

$5 \mathrm{~m}$
$5 \mathbf{i}$<smiles>CC(C)(C)C(=O)CN1C(=O)C(Br)=C(c2ccccc2)C12CC=CCC2O</smiles><smiles>O=C(CN1C(=O)C(Br)=C(c2ccccc2)C12C=CC=CC2)c1ccccc1</smiles><smiles>CC(=O)CN1C(=O)C(Br)=C(c2ccc(C)cc2)C12CC=CCC2O</smiles>

5j

Figure S5. Structure of compound 5. 
Structure of compound $(6,7)$

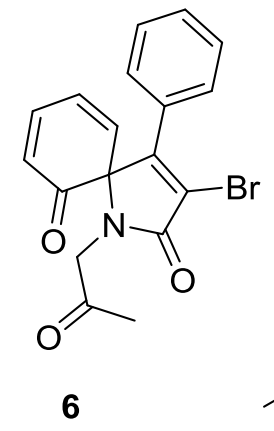

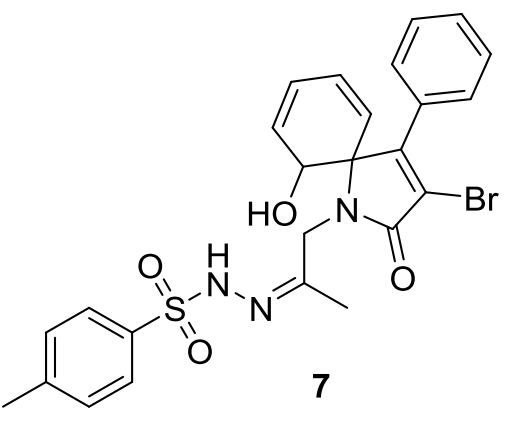

Figure S6. Structure of compound 6 and 7. 

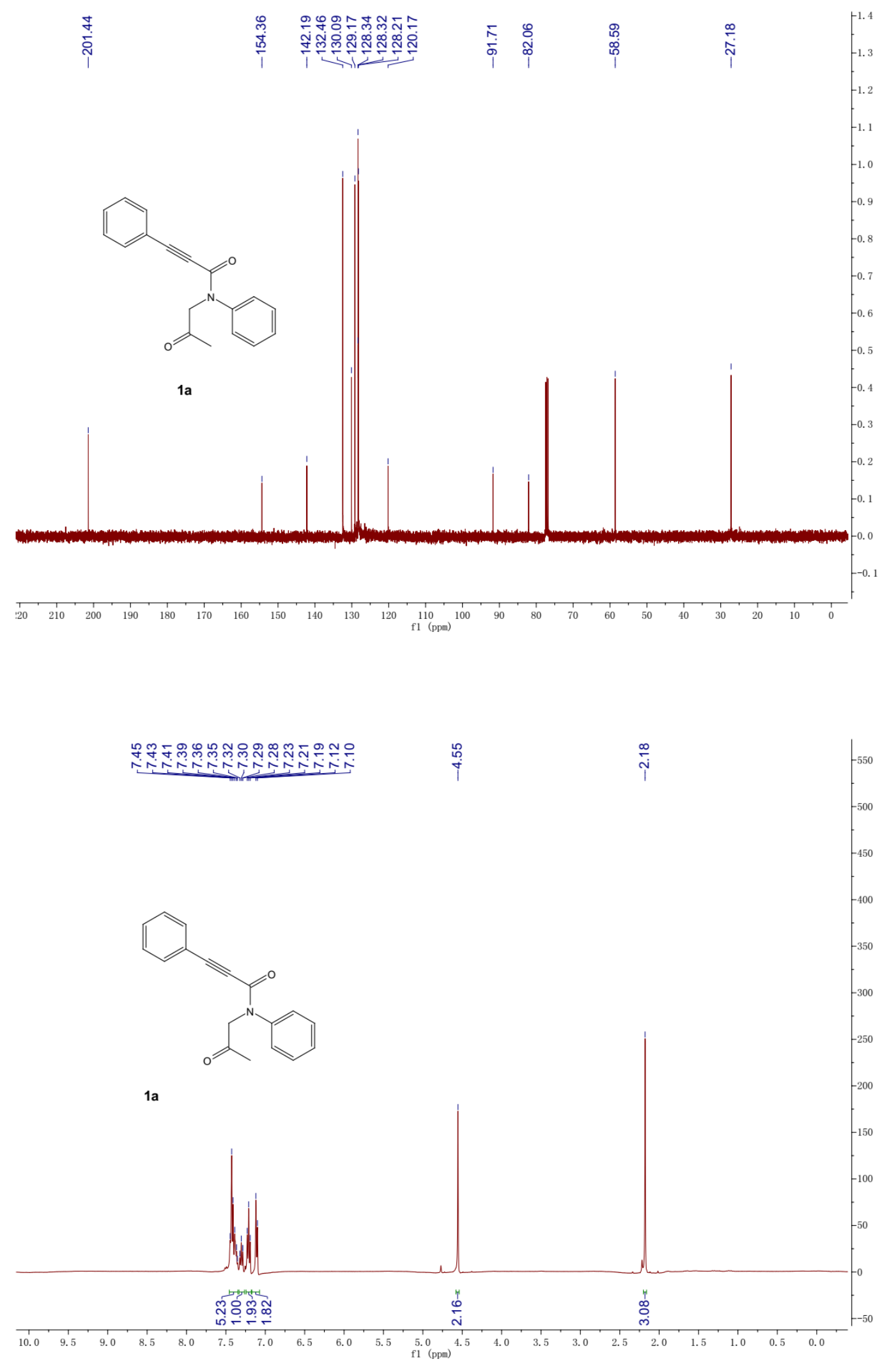

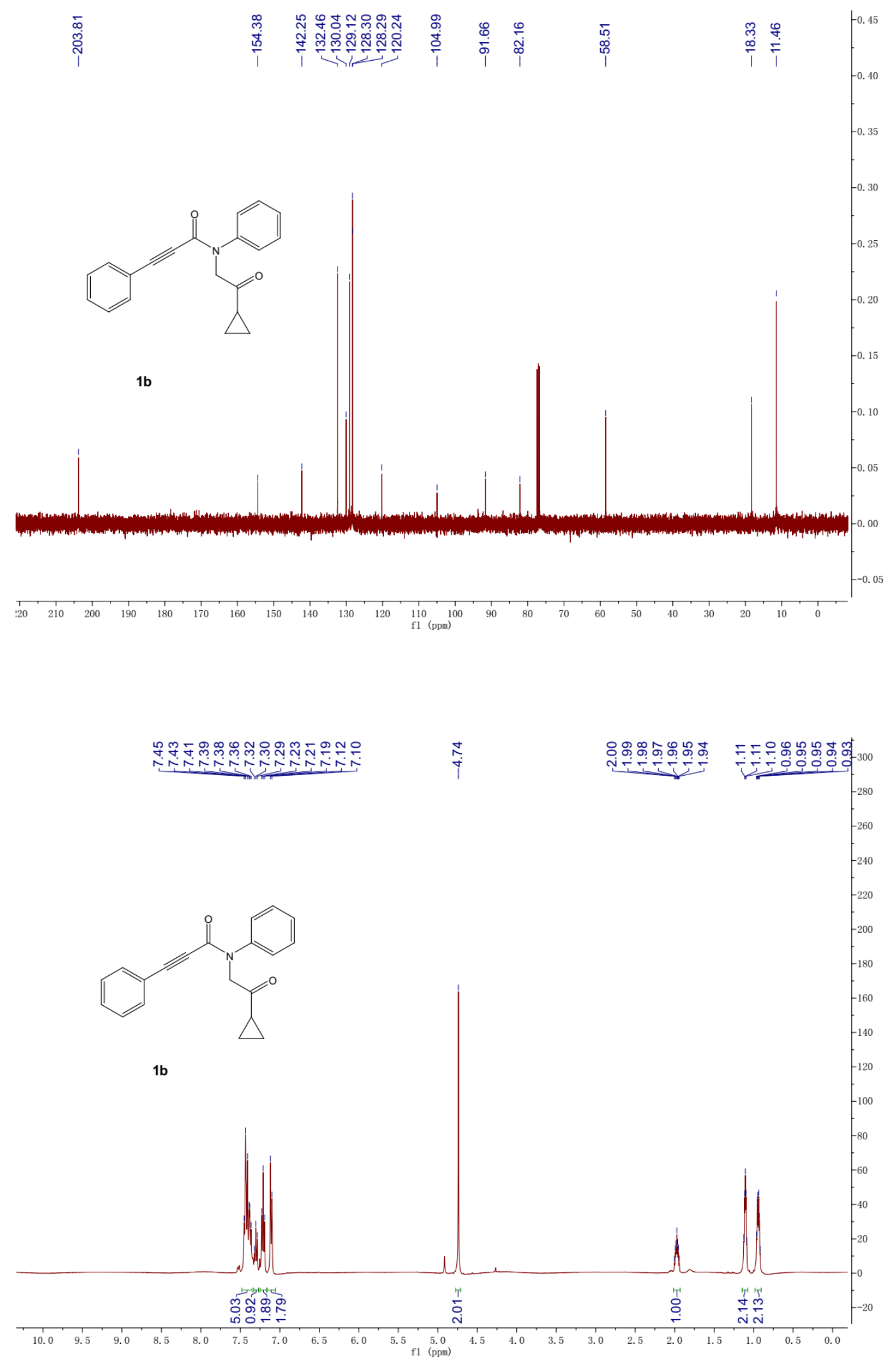

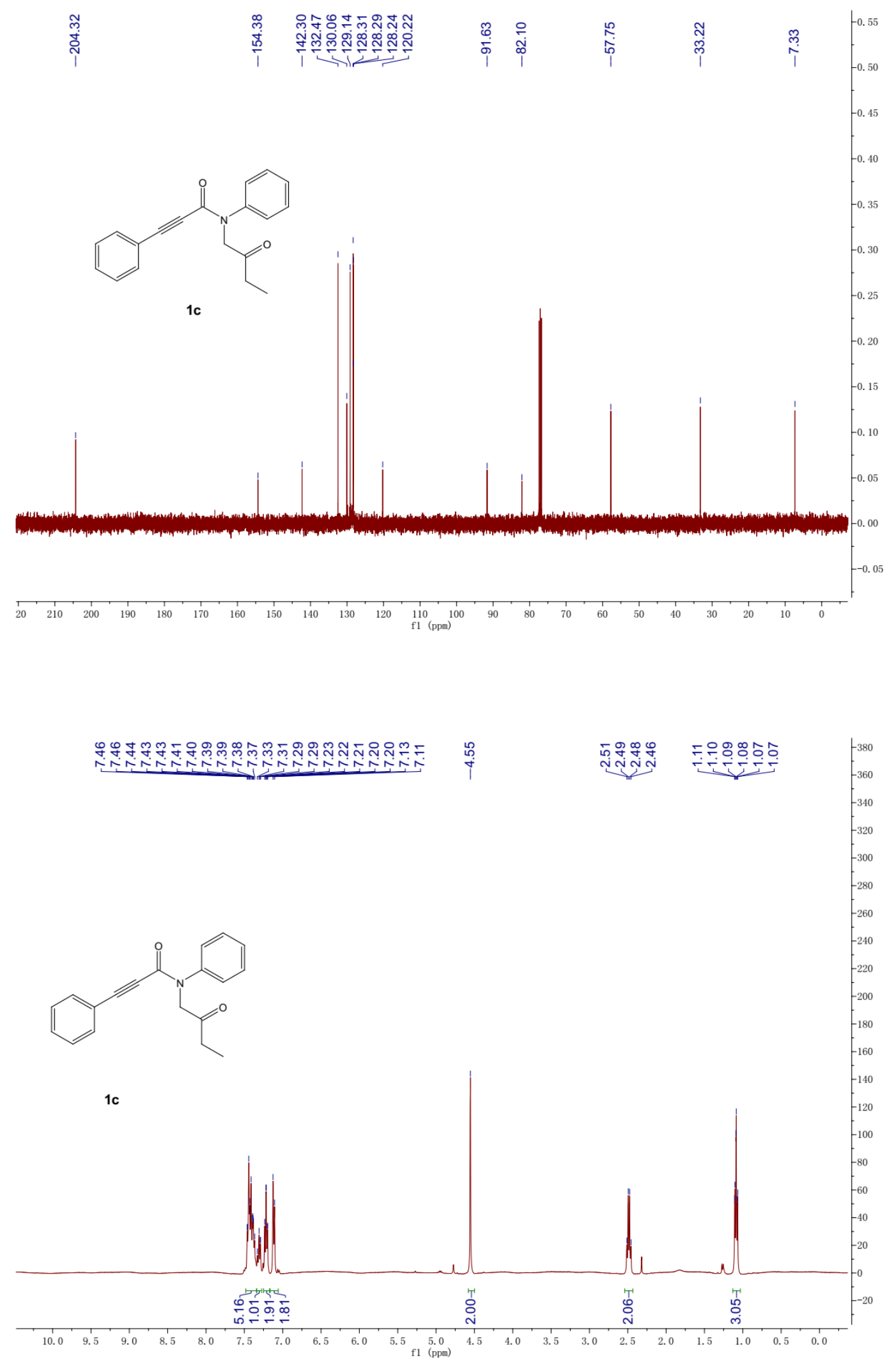

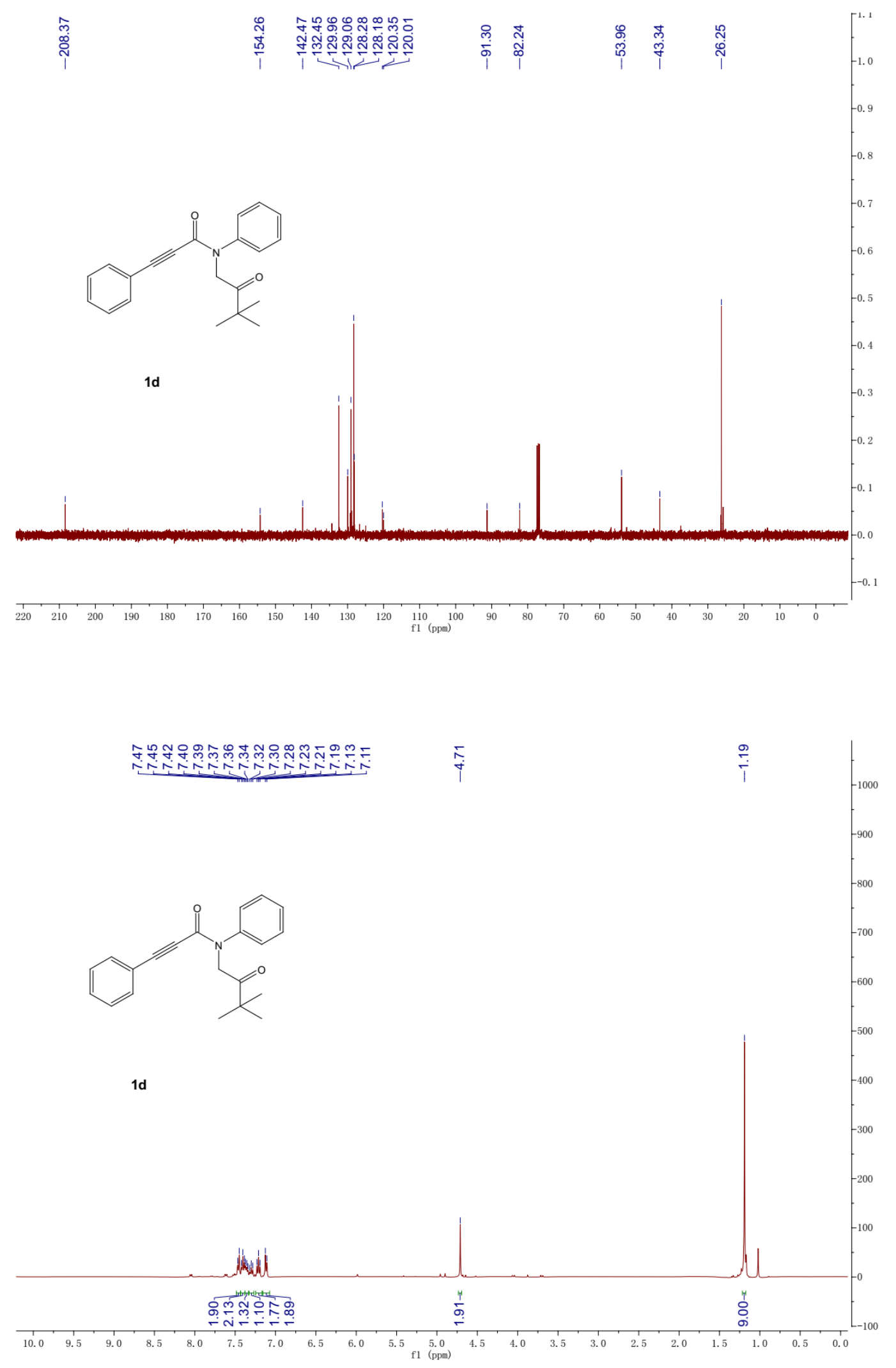

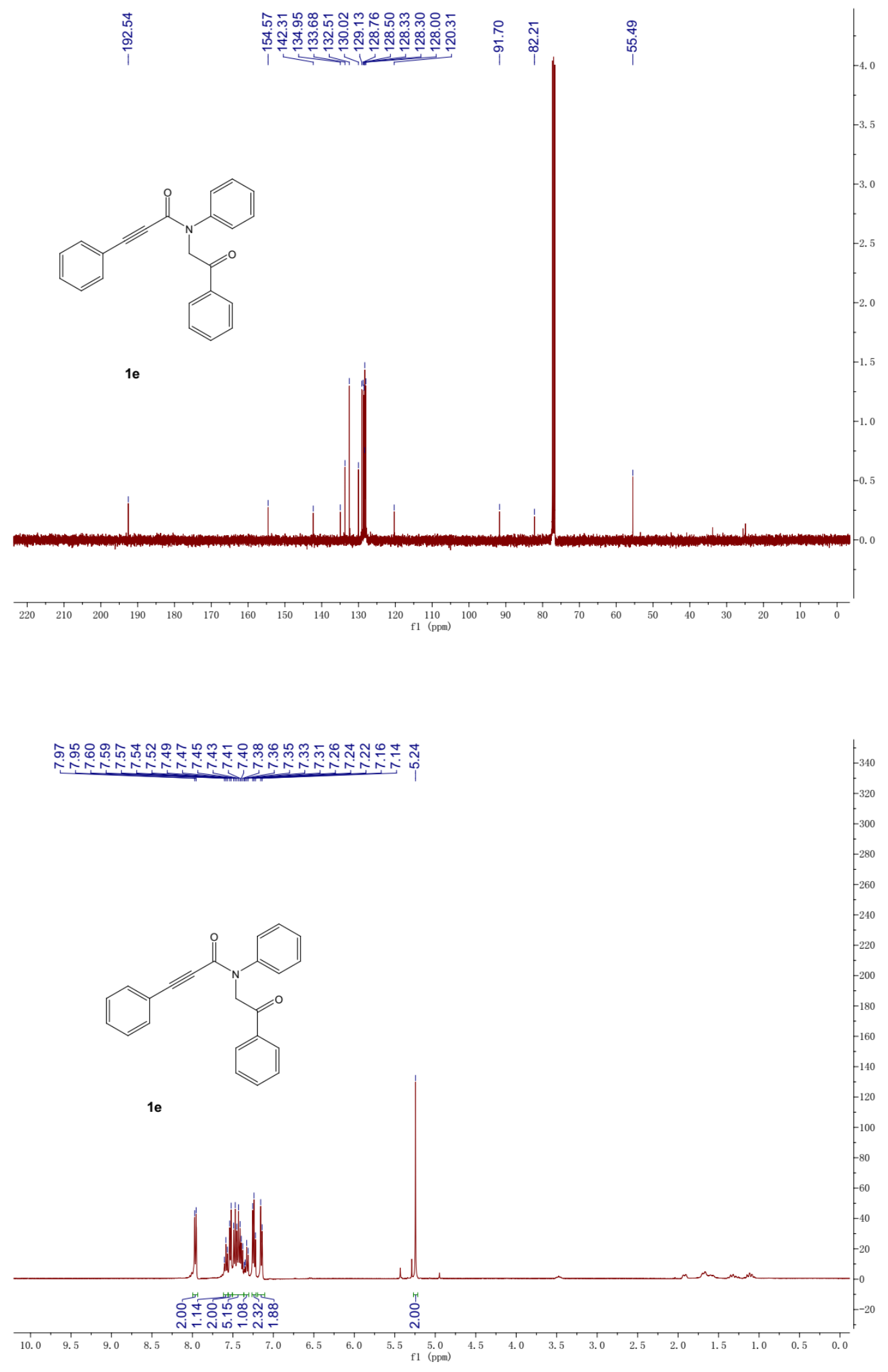

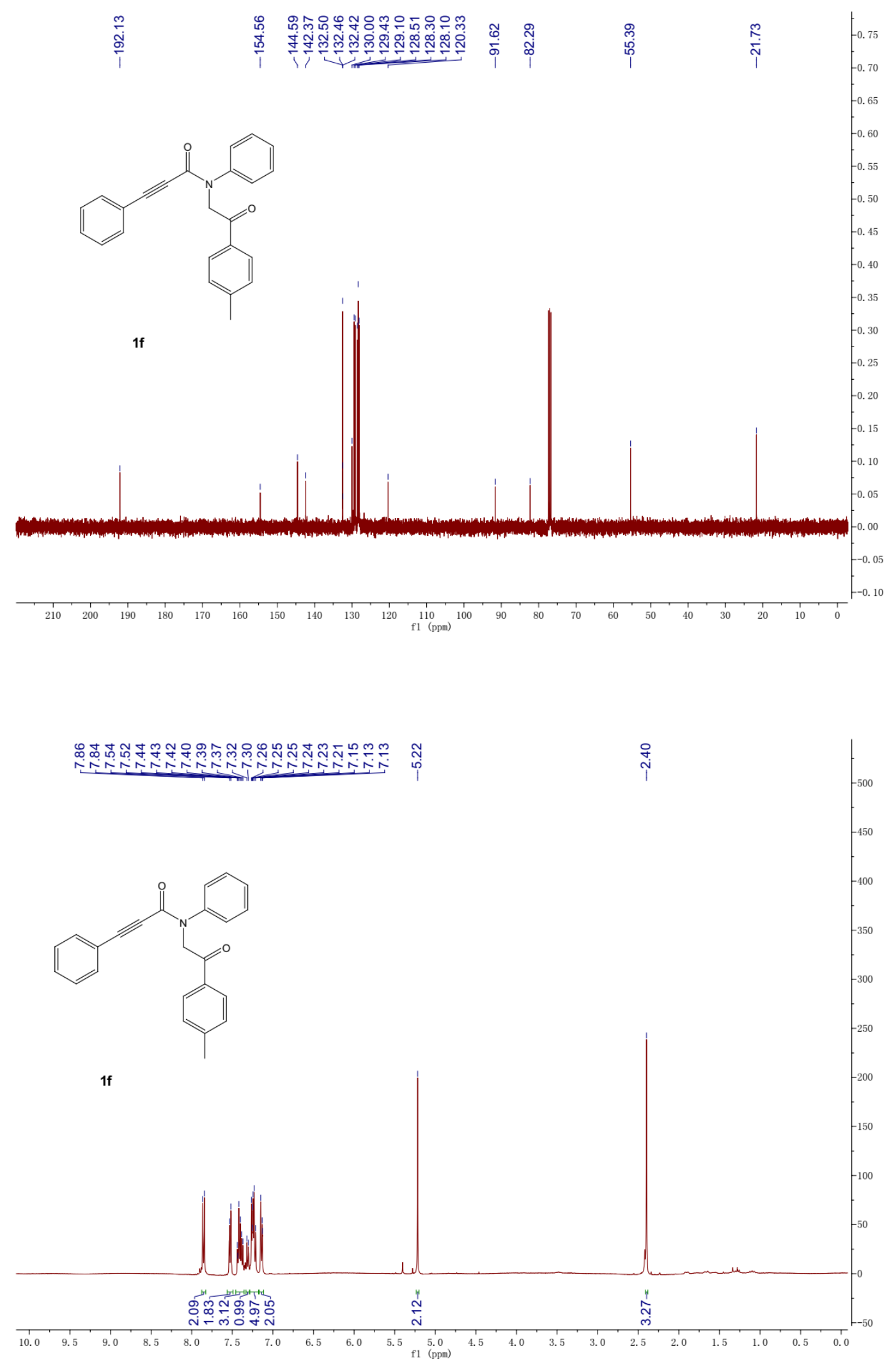

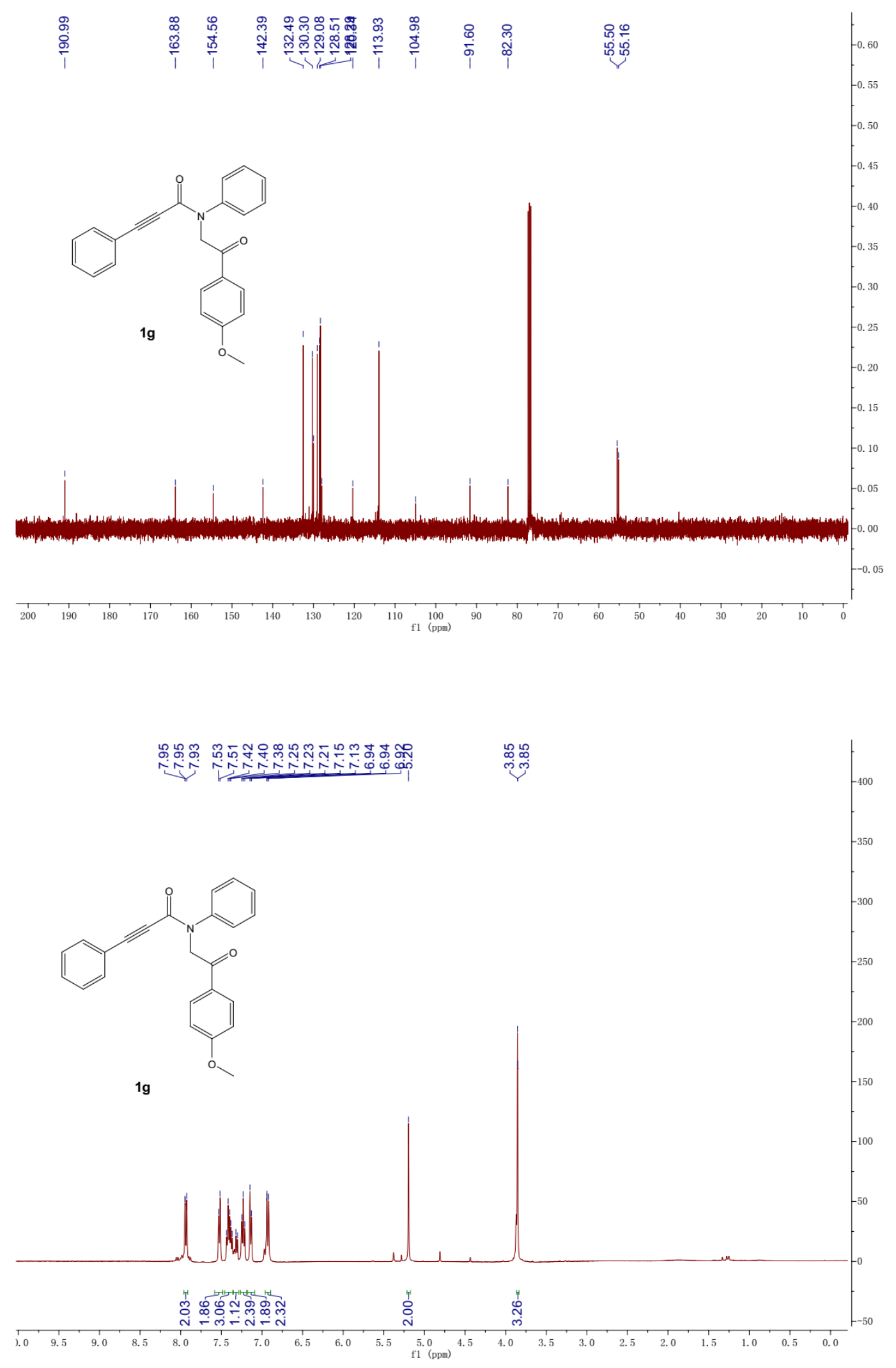

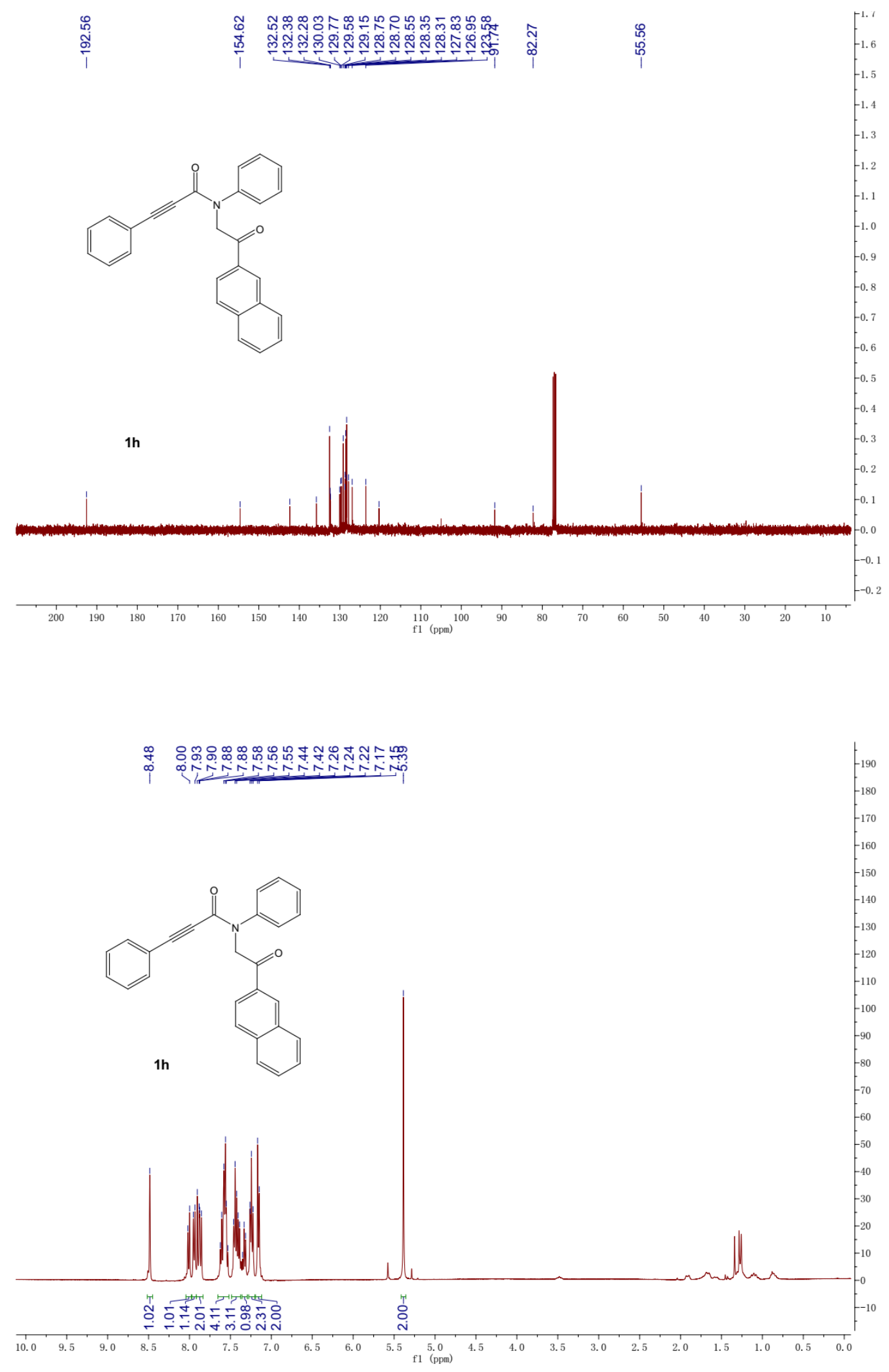

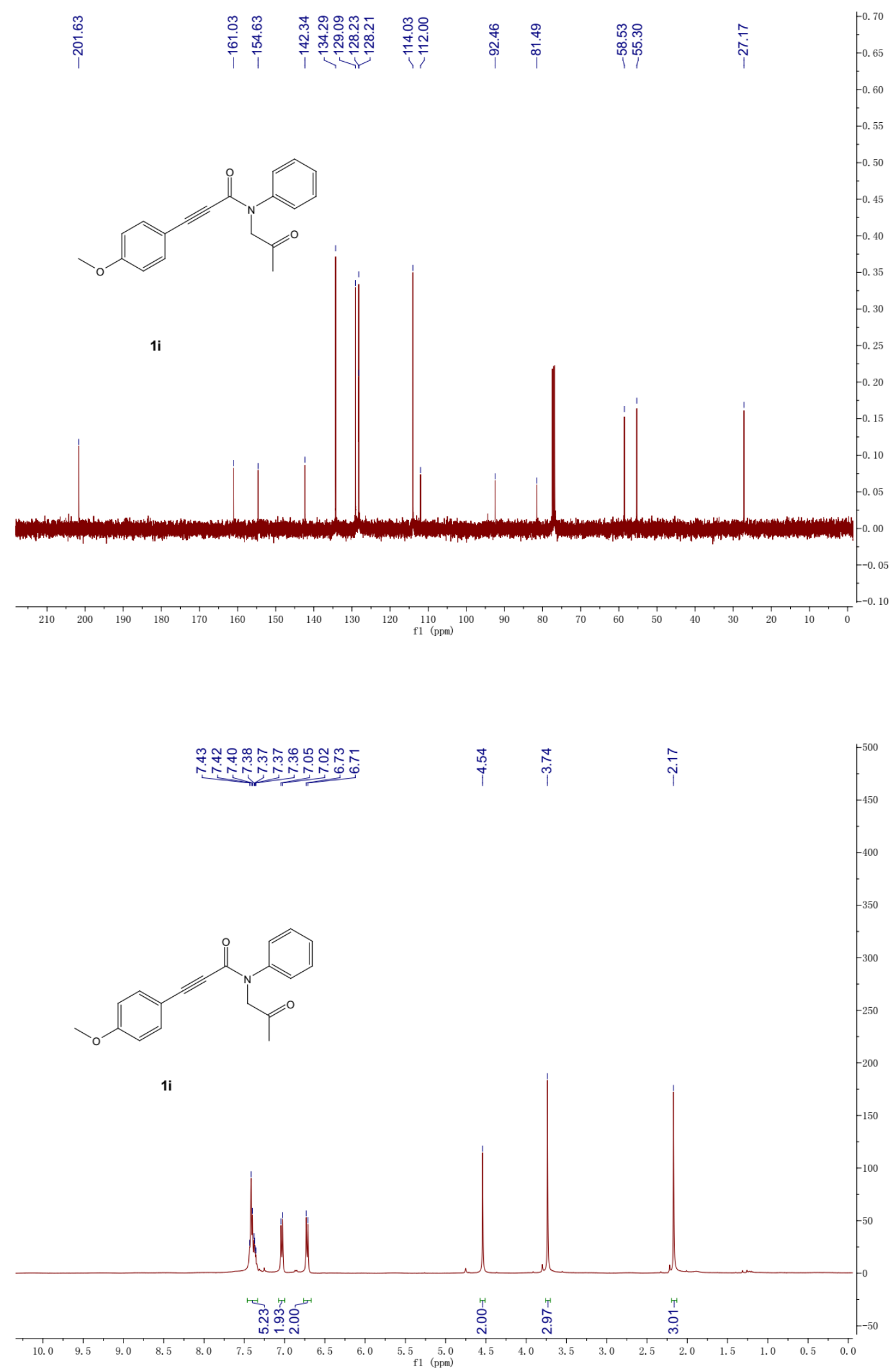

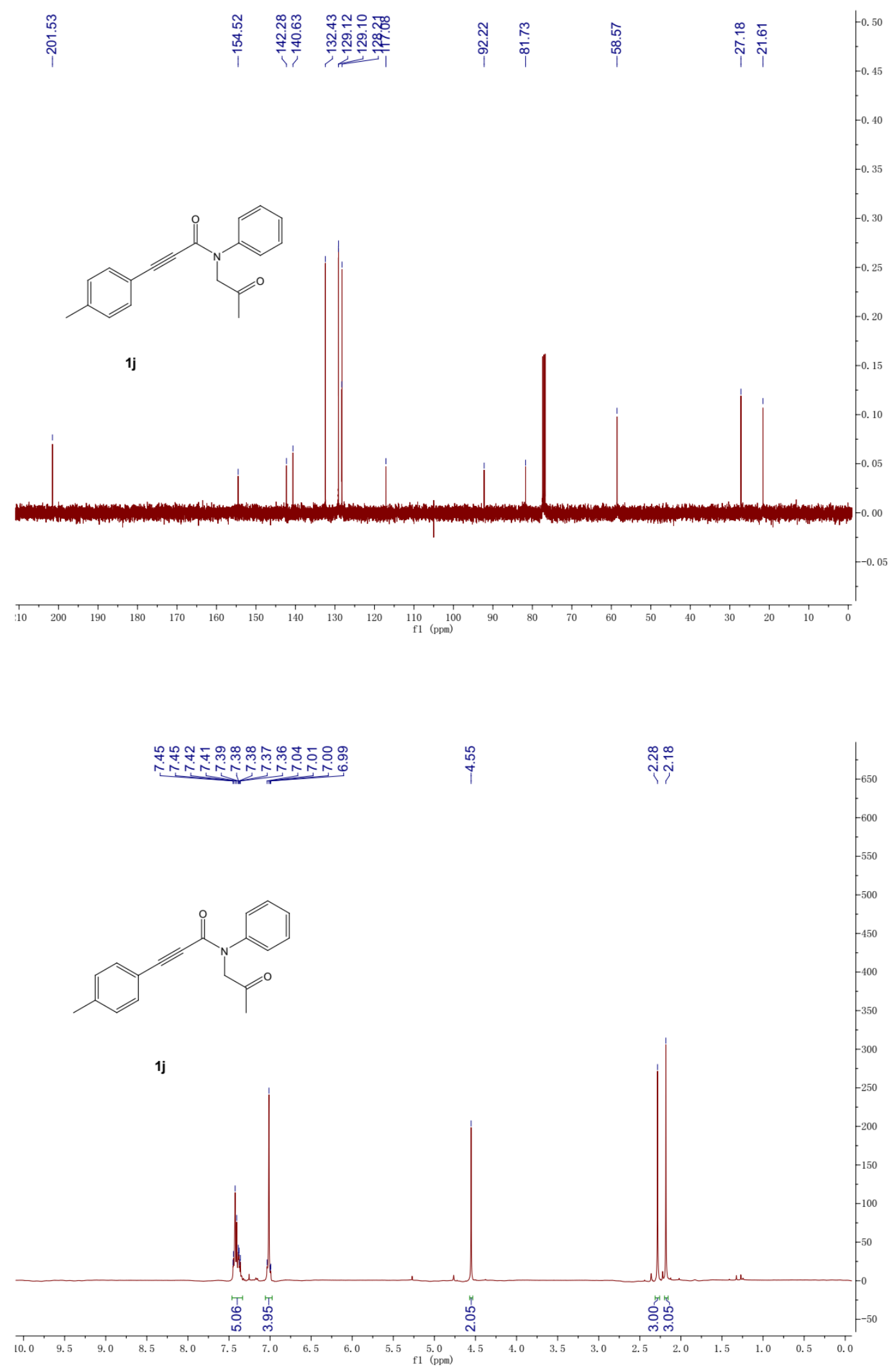

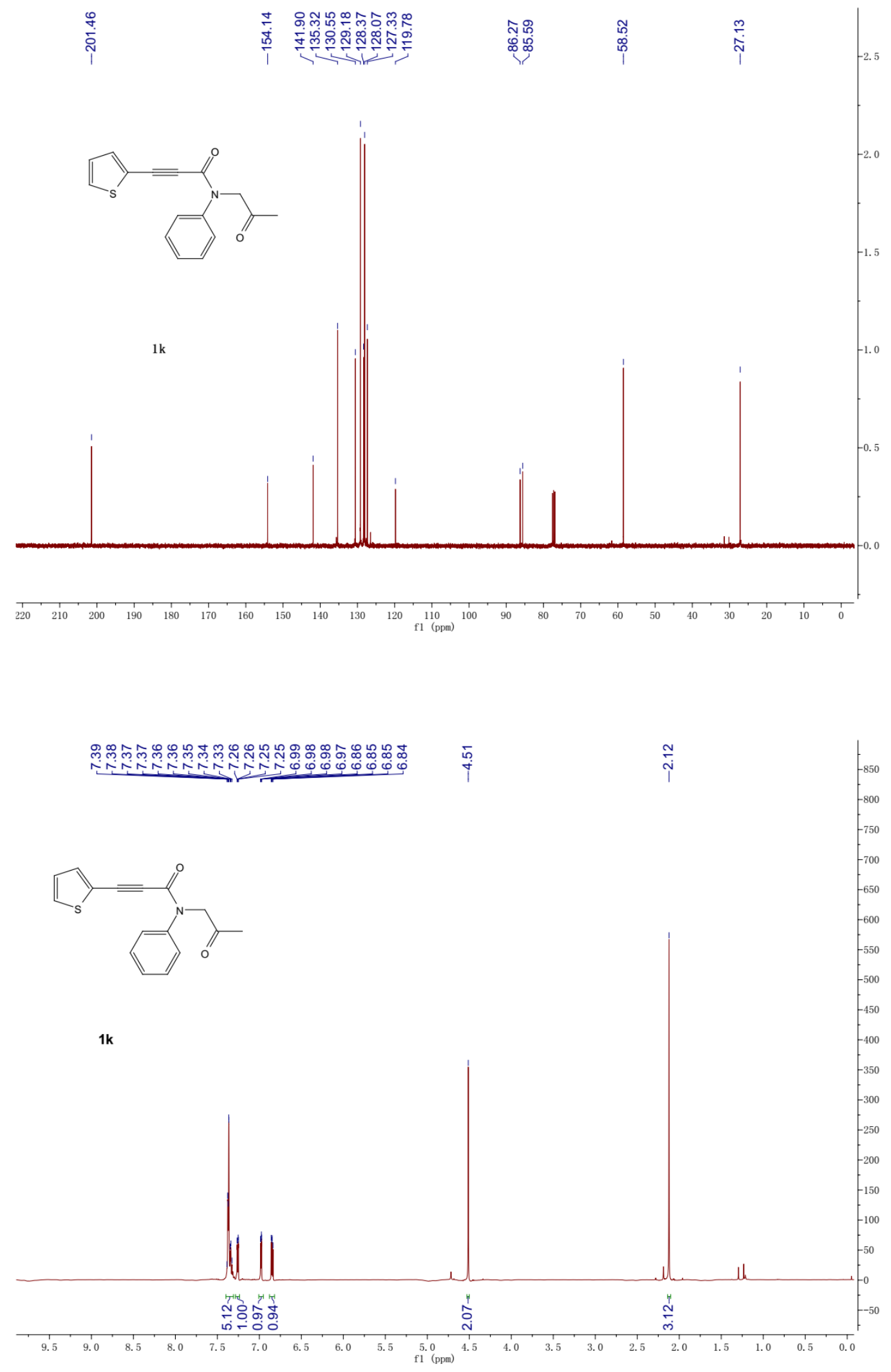


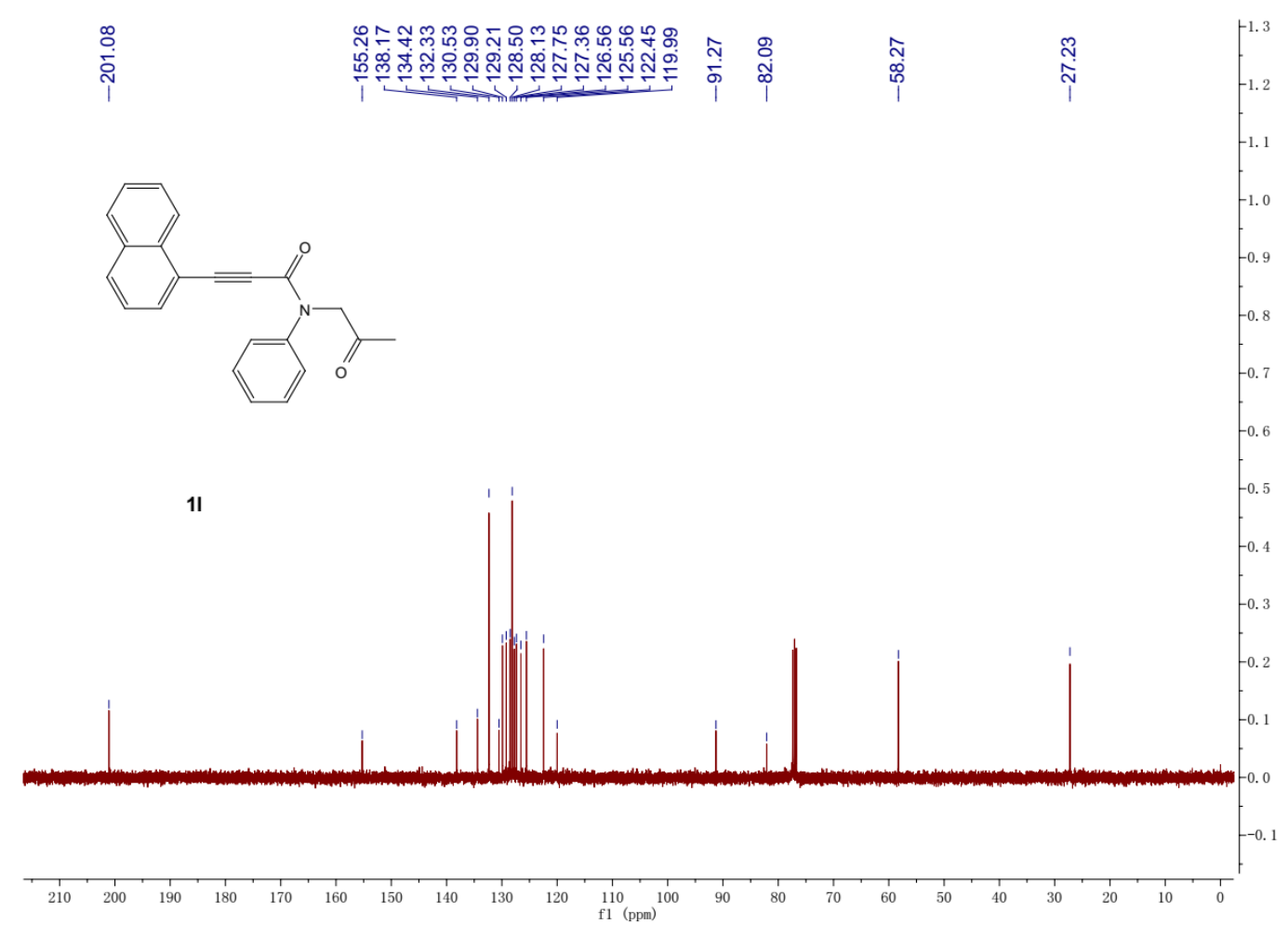

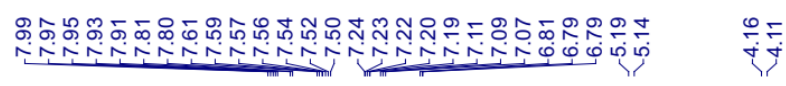

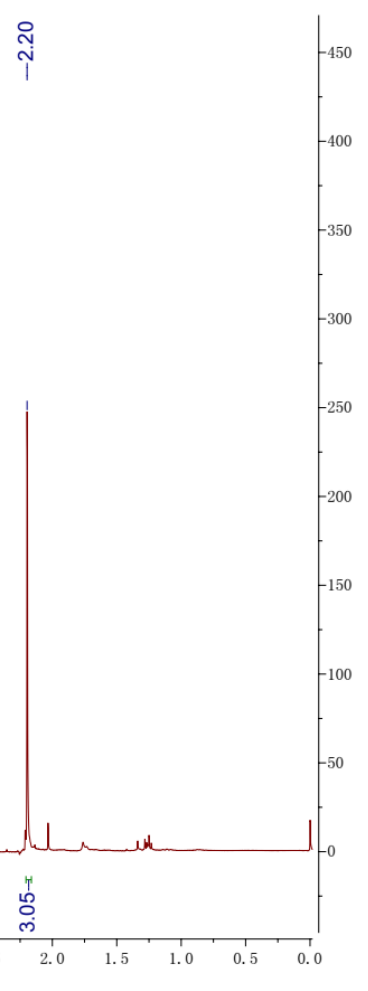



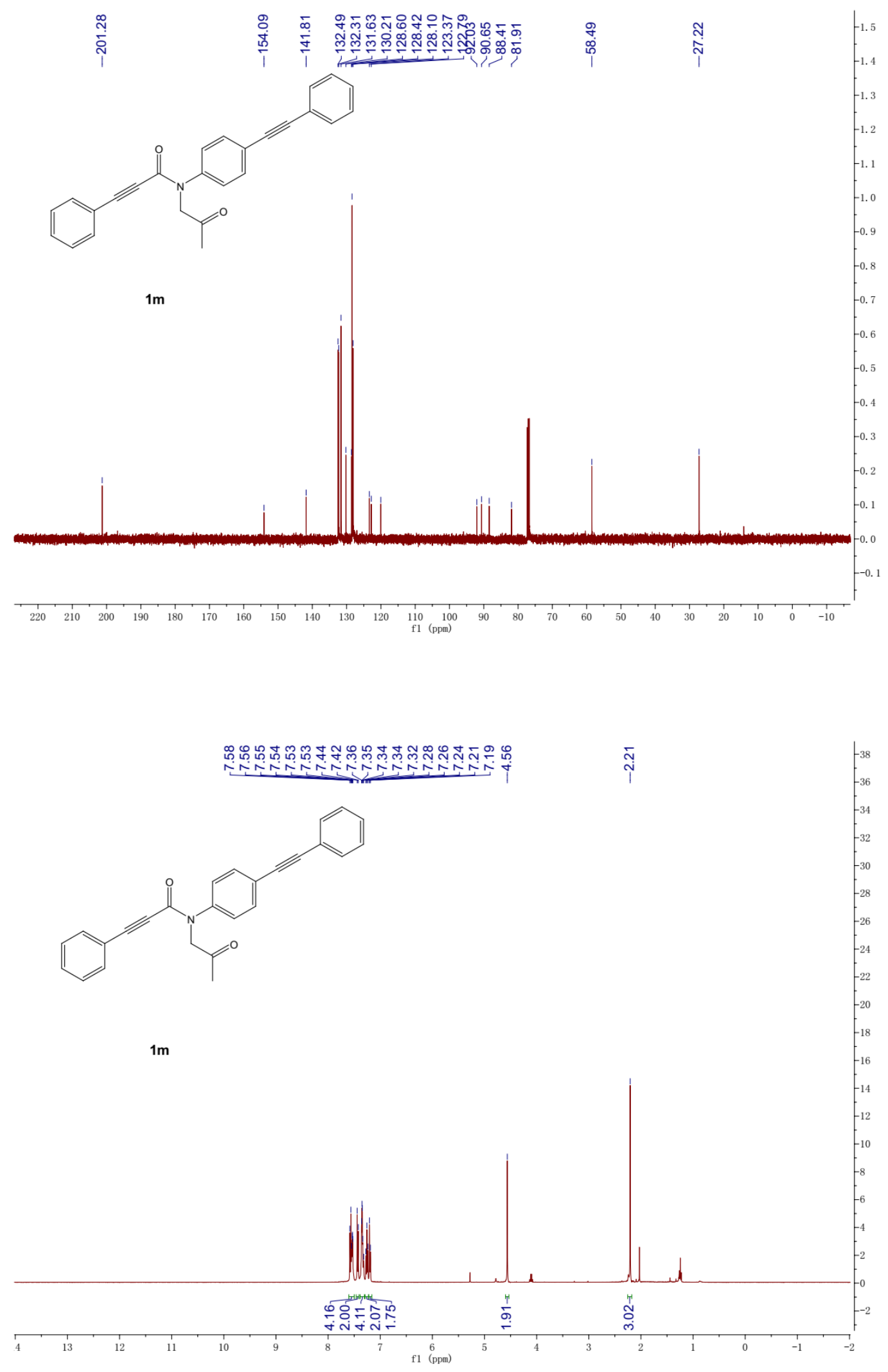

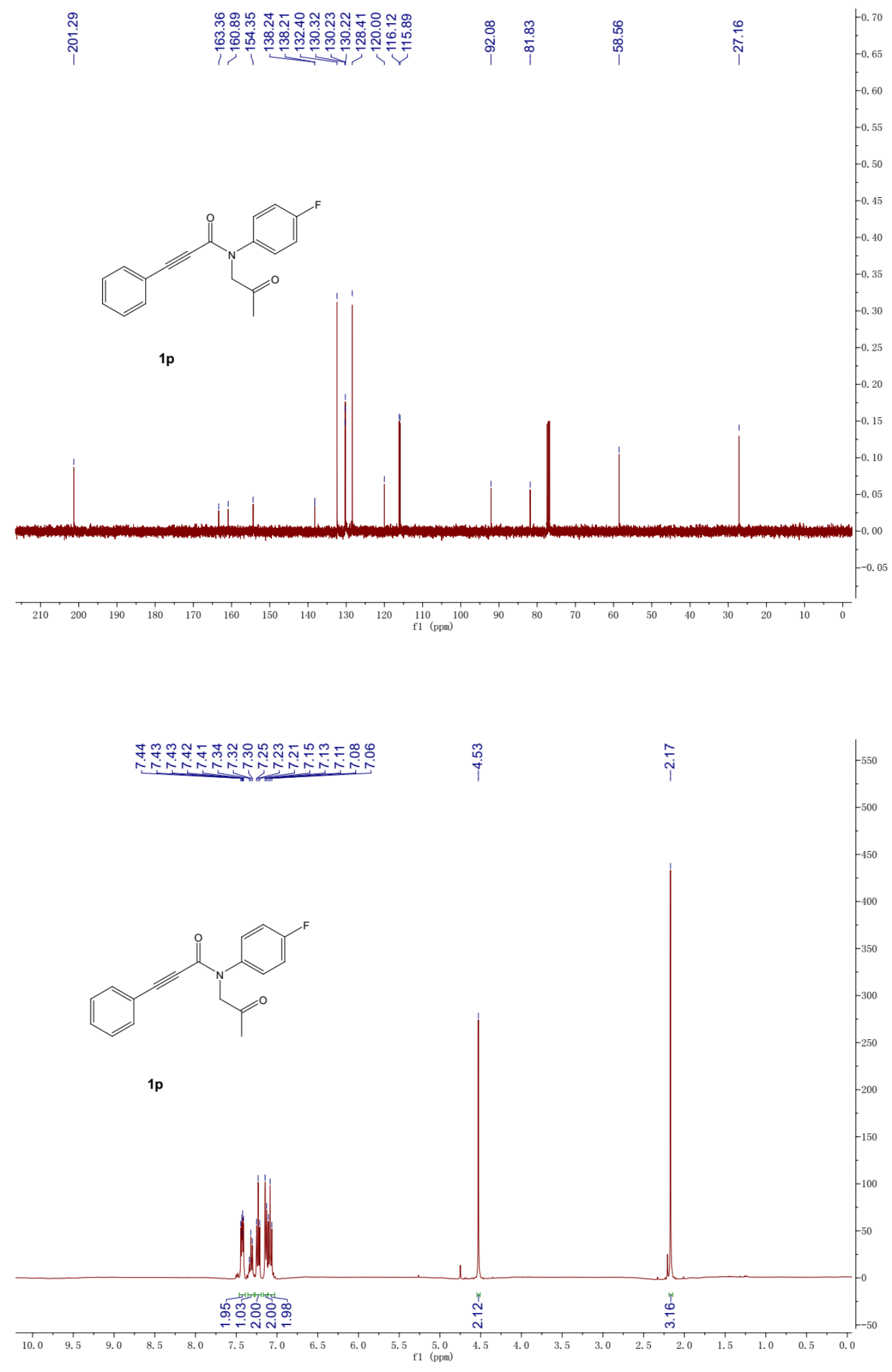


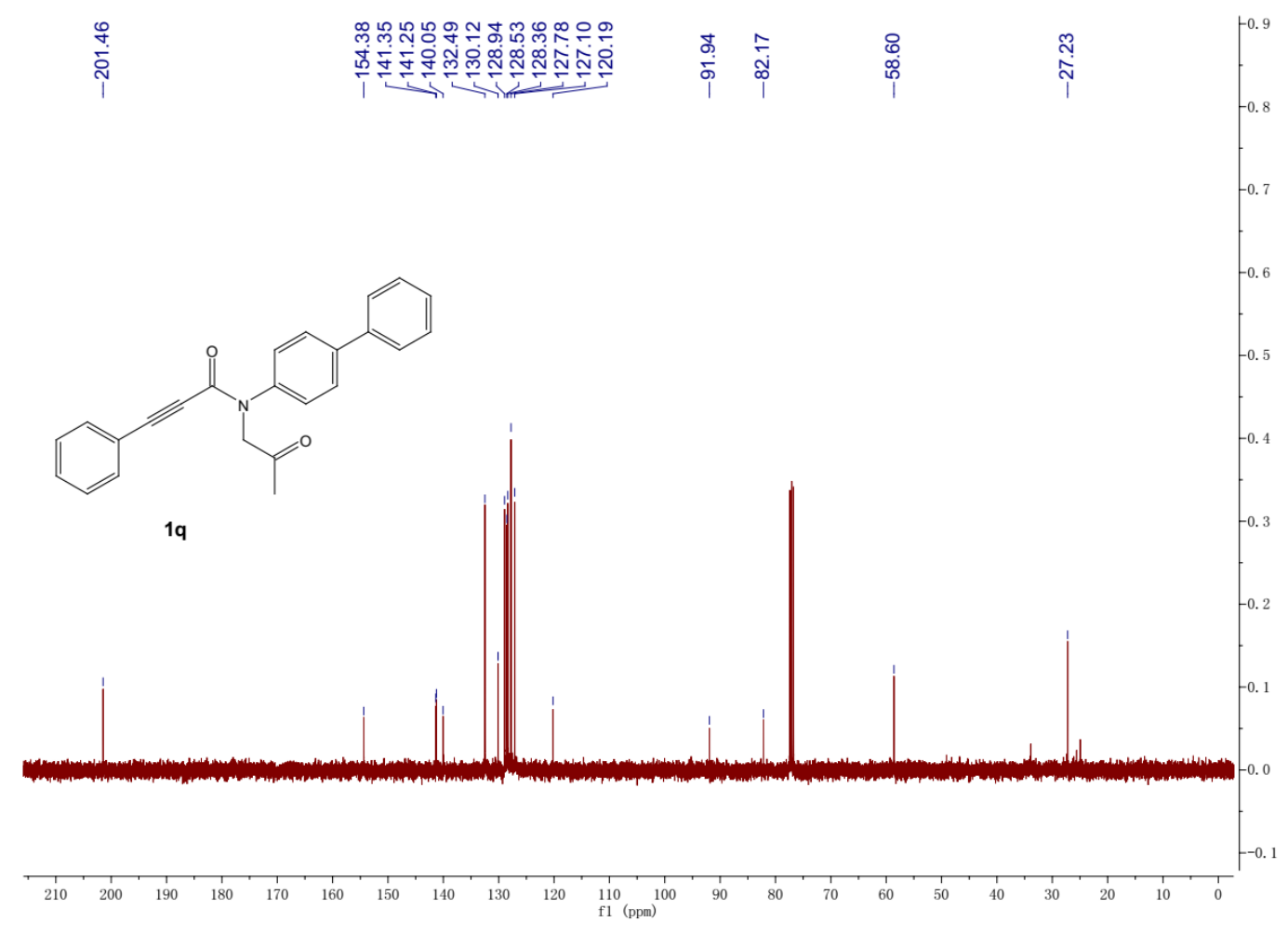

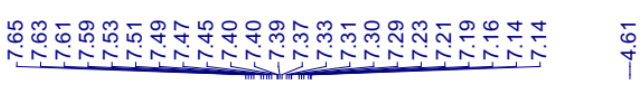

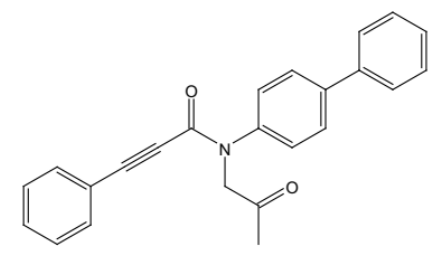

$1 q$

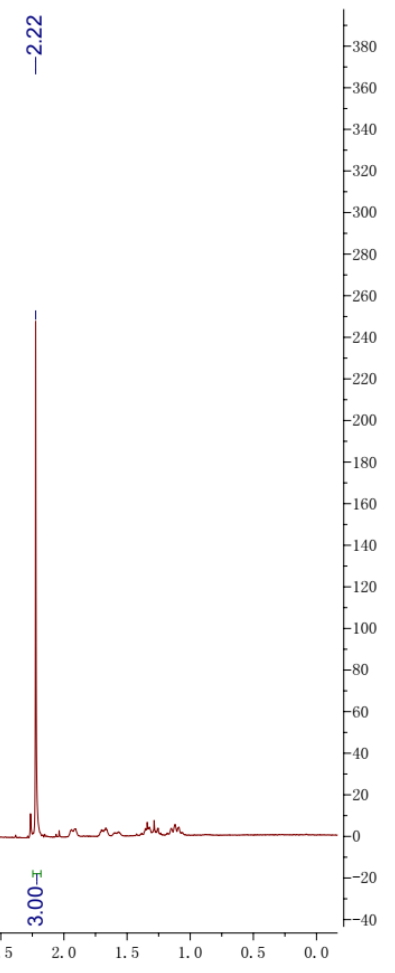



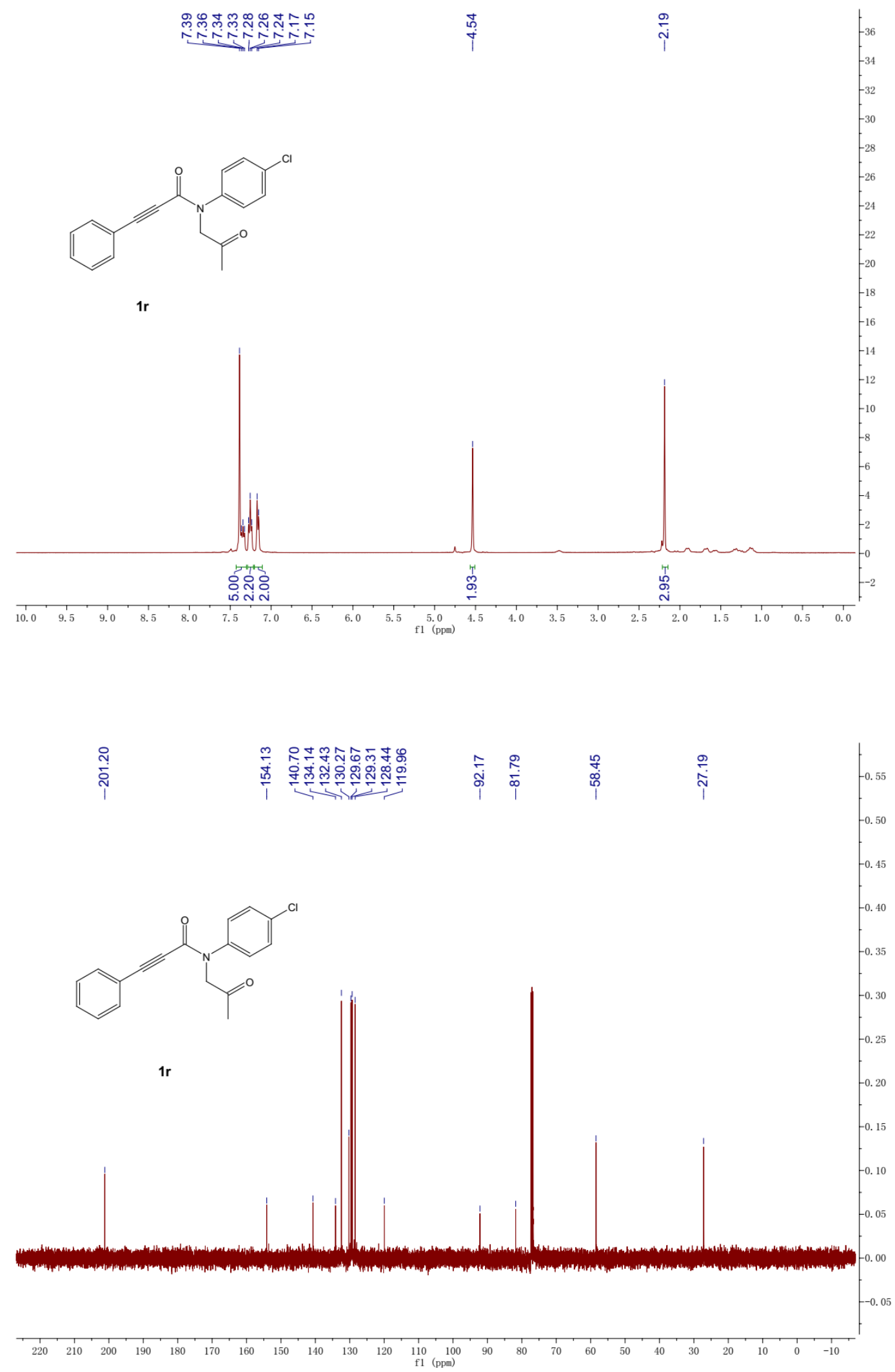

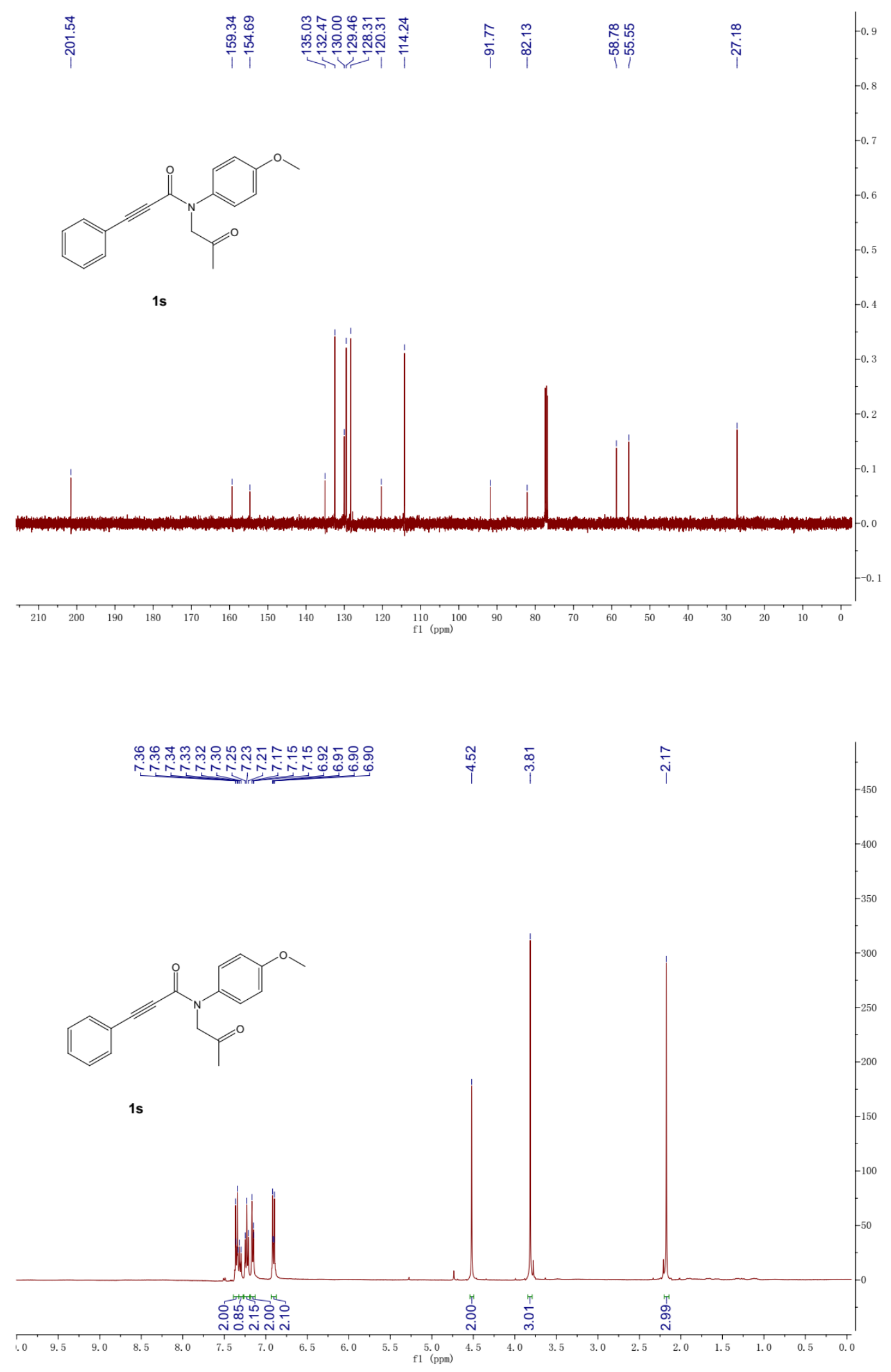

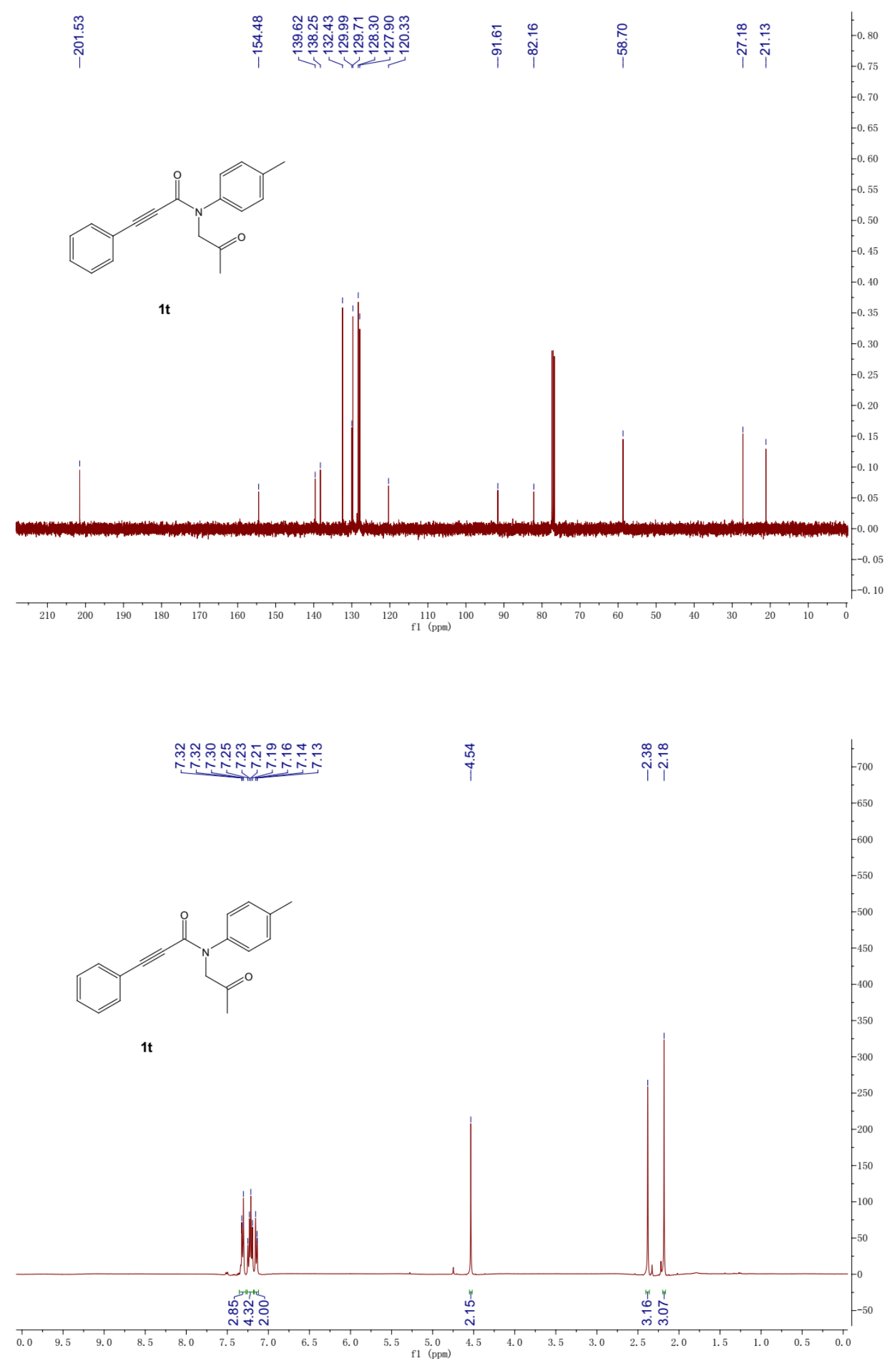

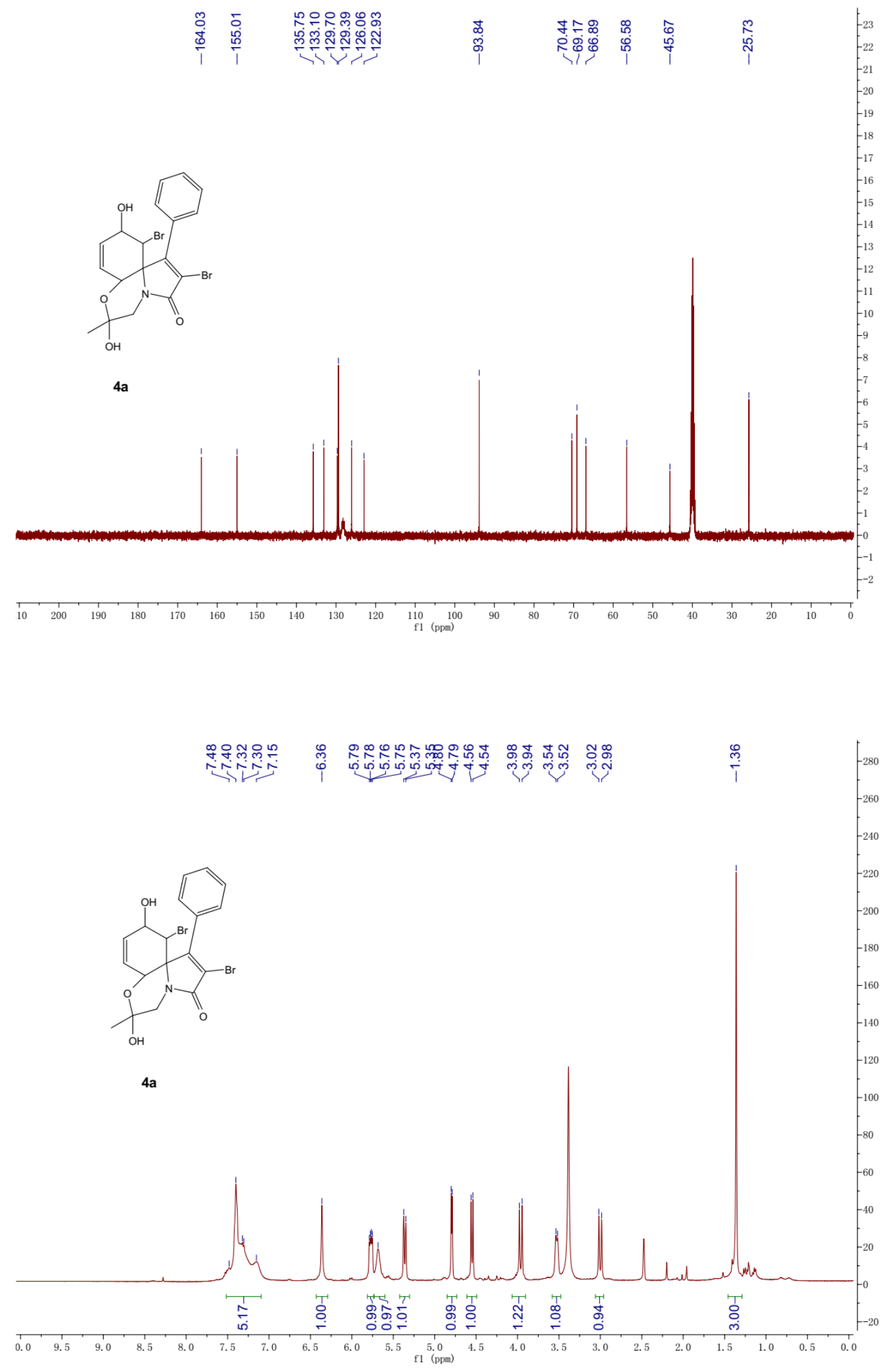

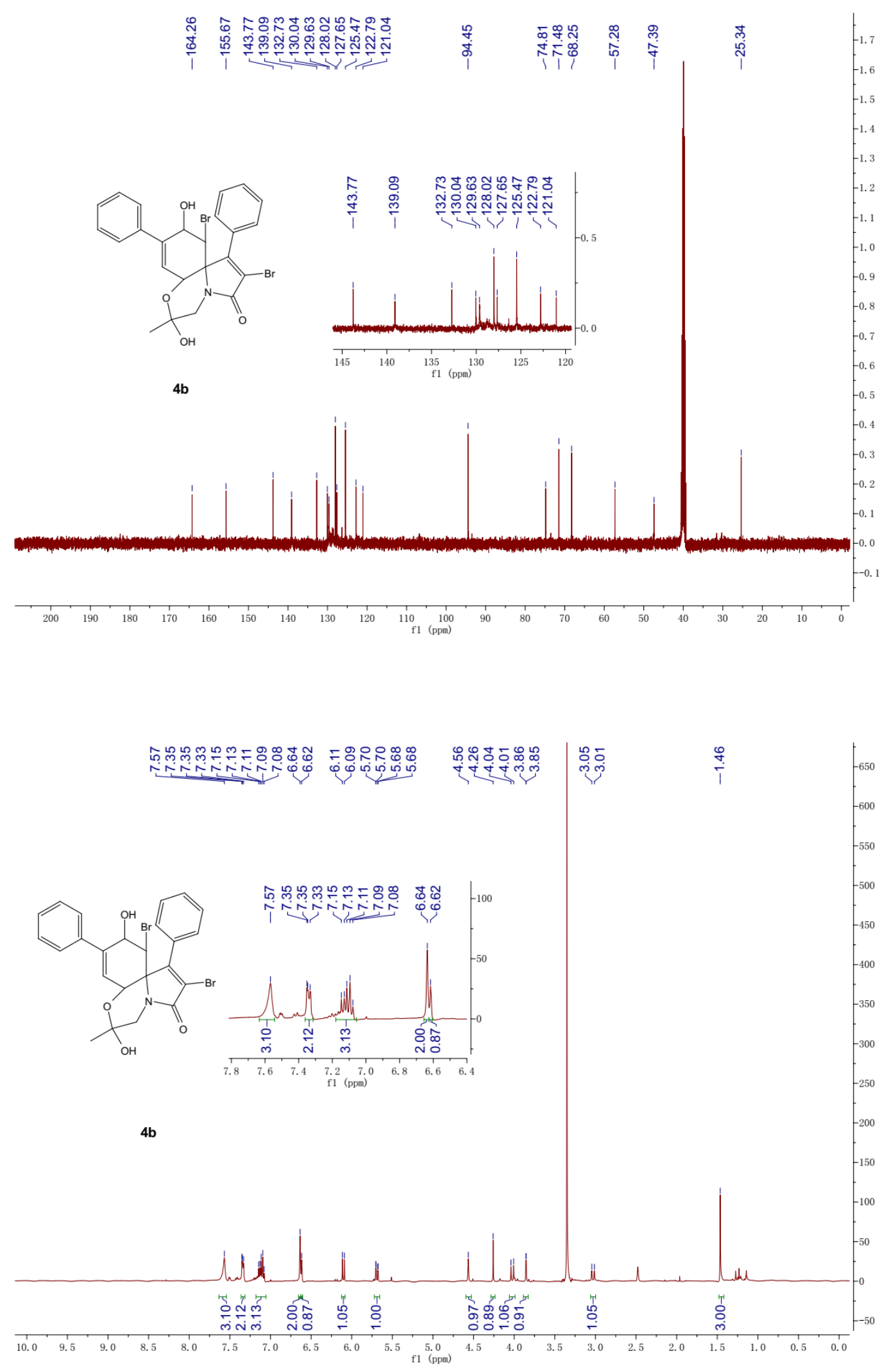

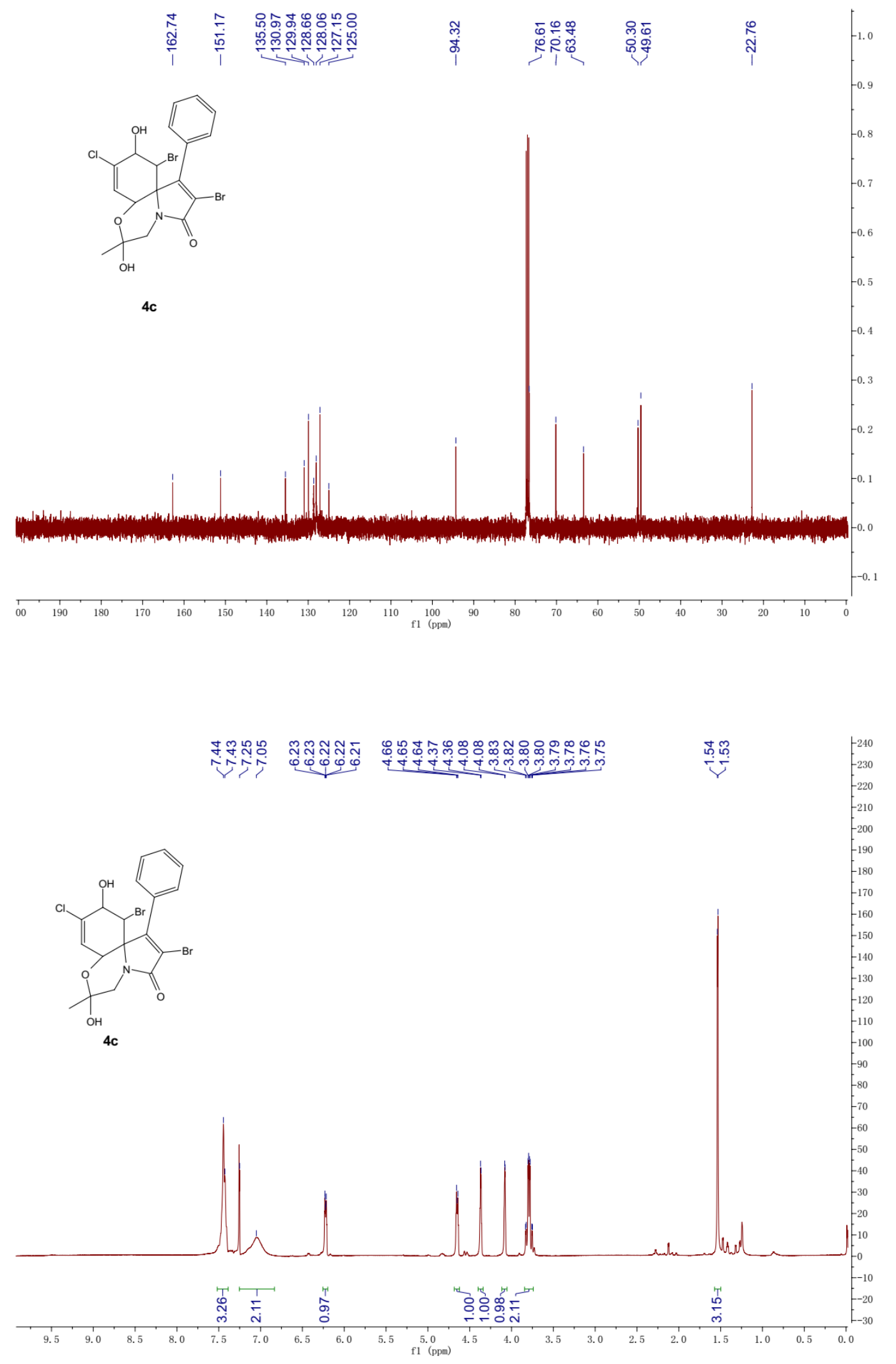

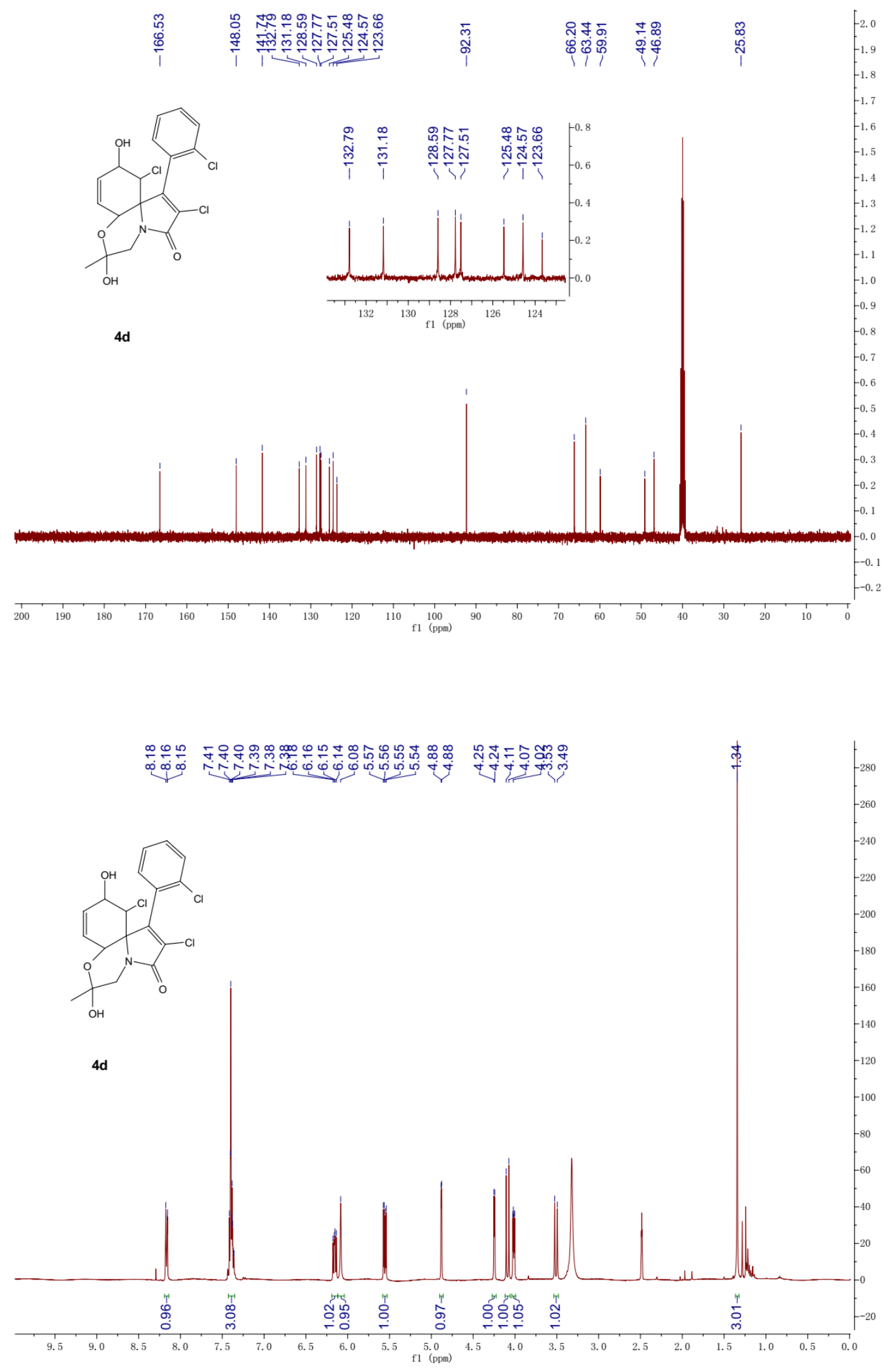

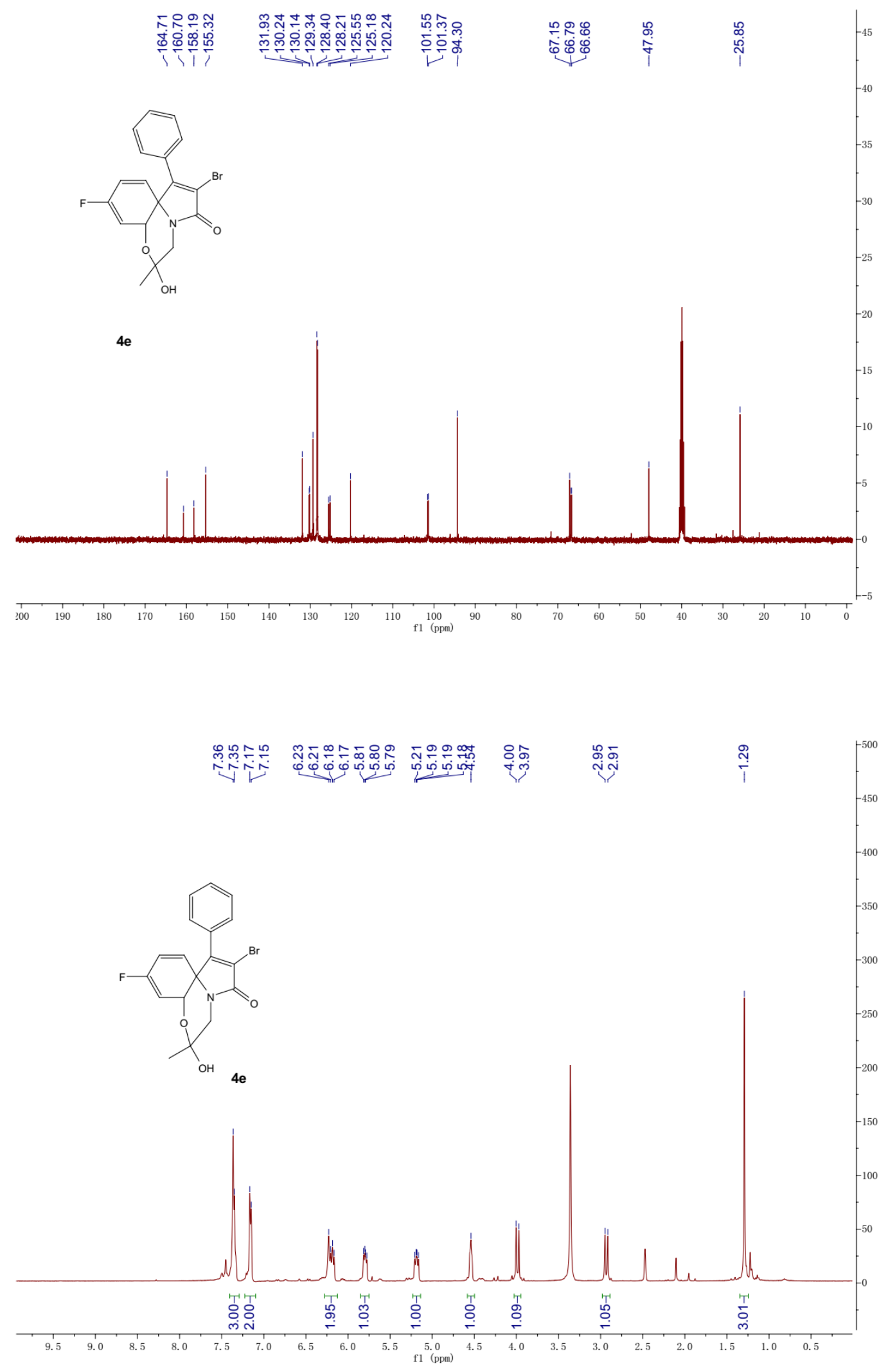


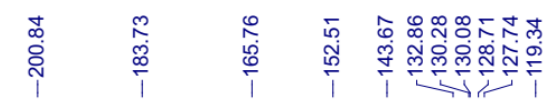

$\infty$
$\infty$
0
0
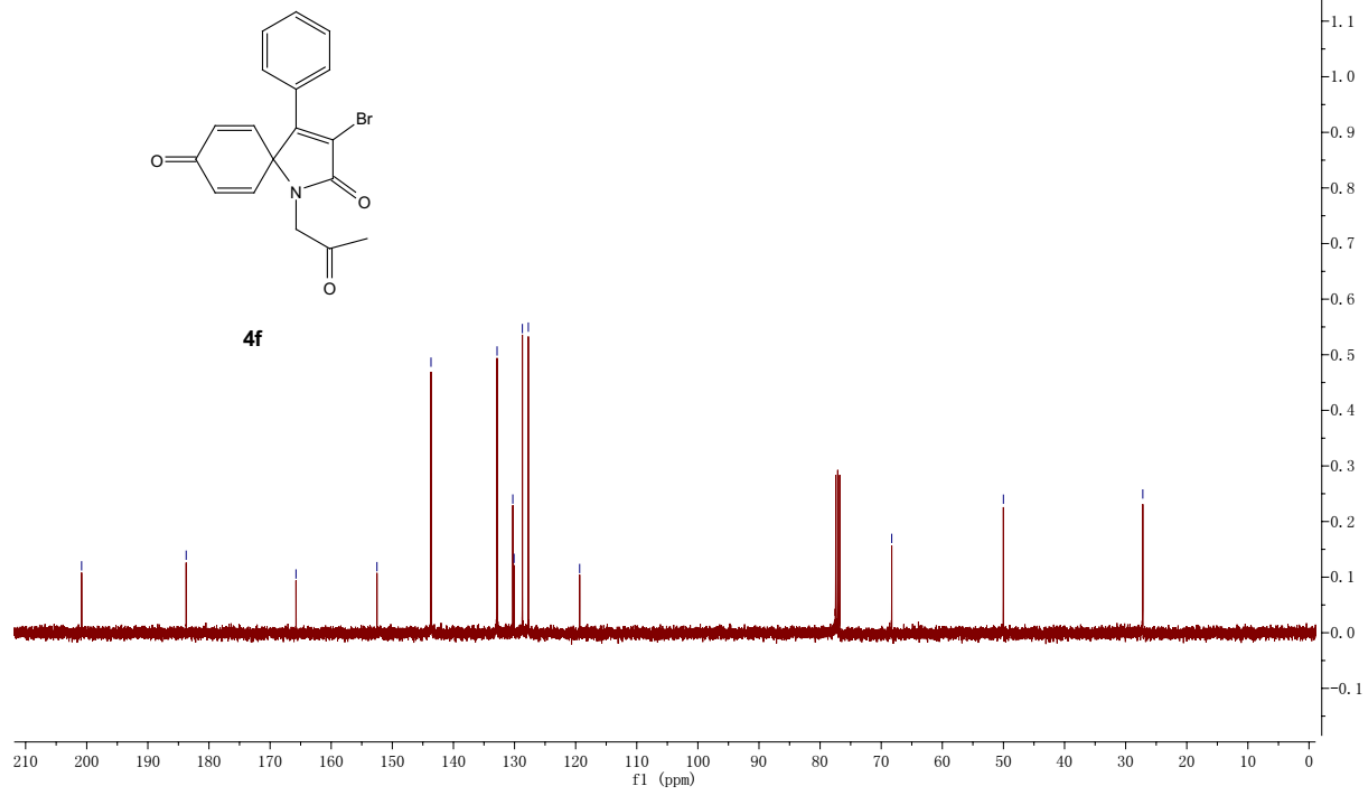

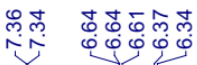

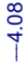

กุำ
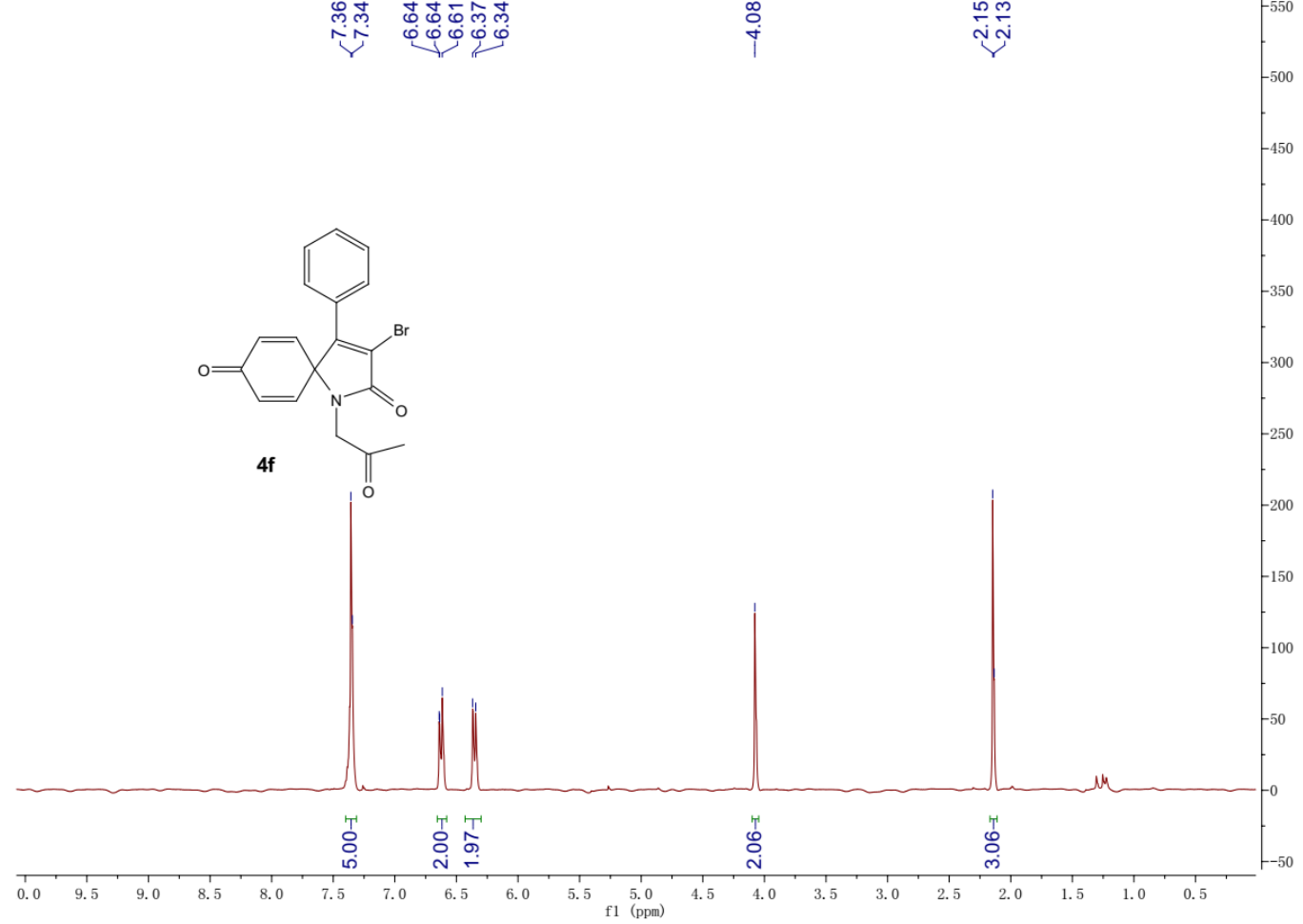

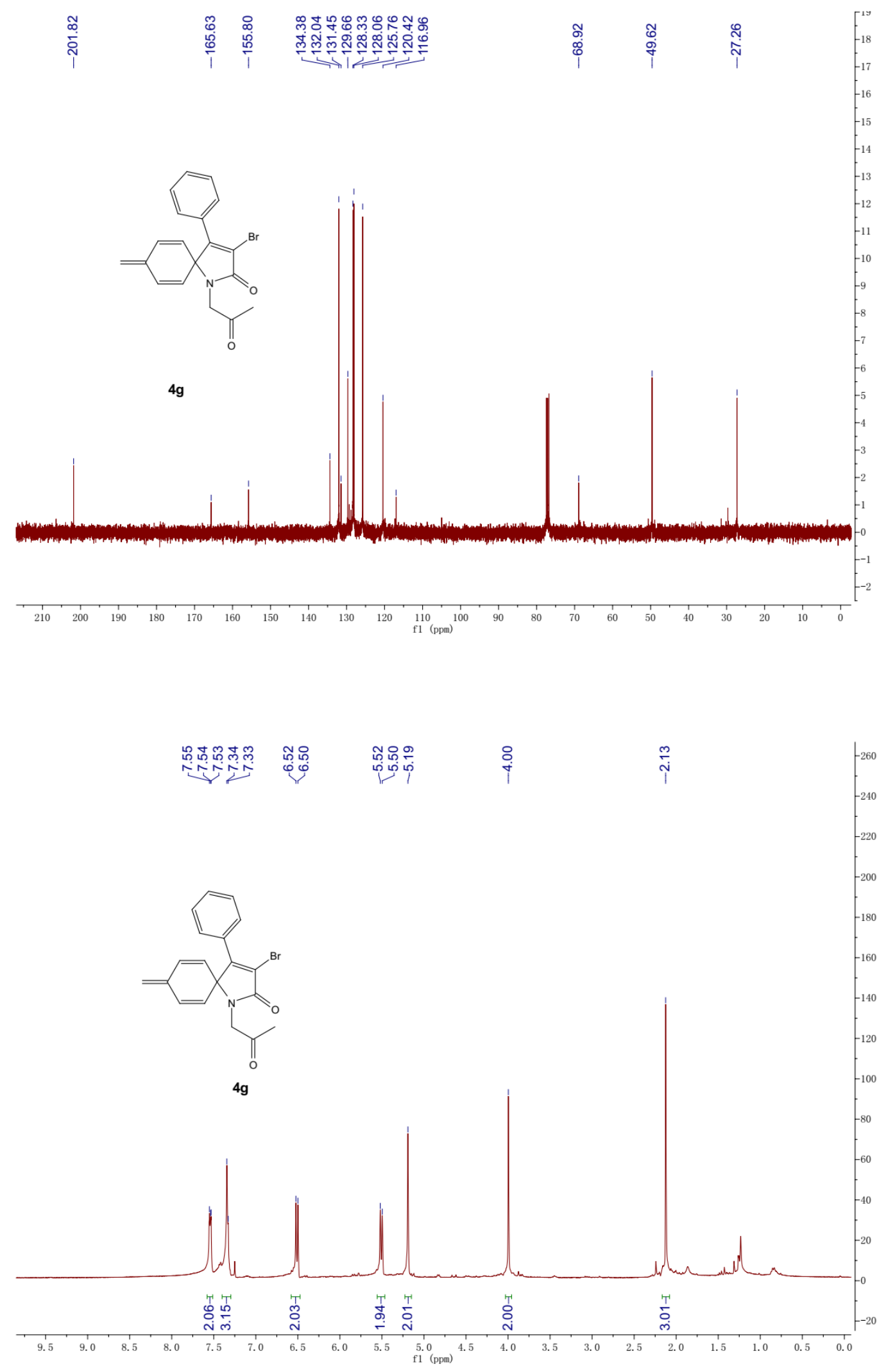


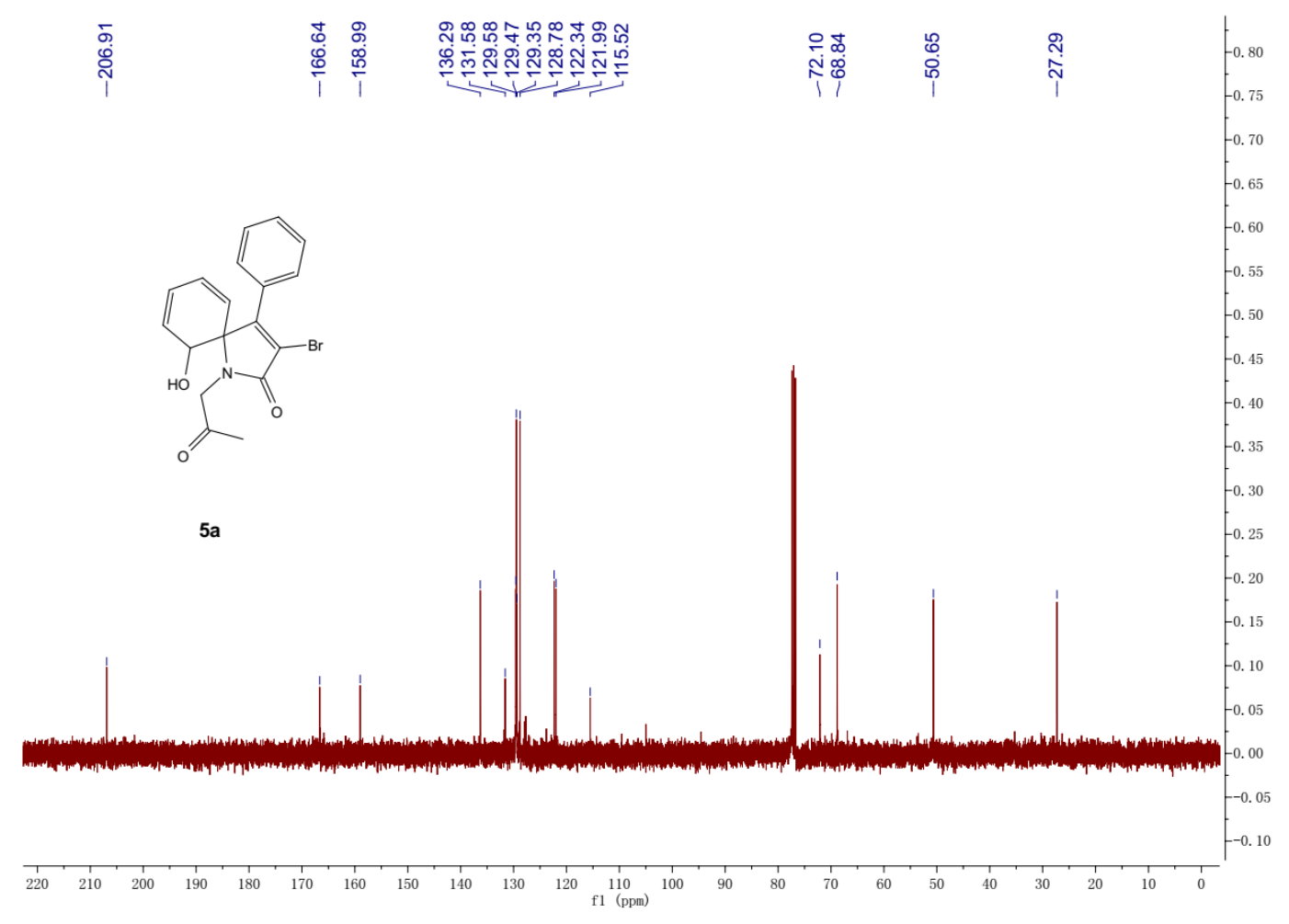

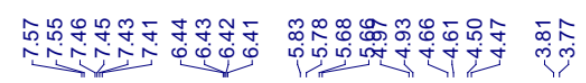
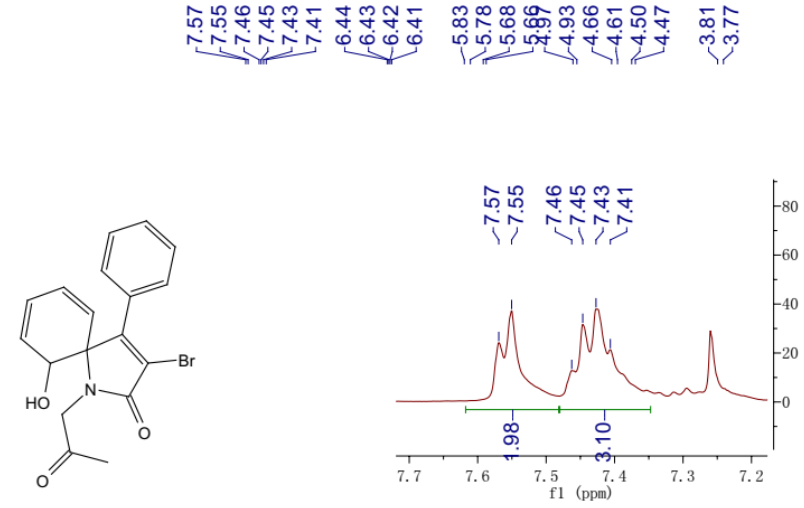

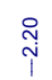

5a

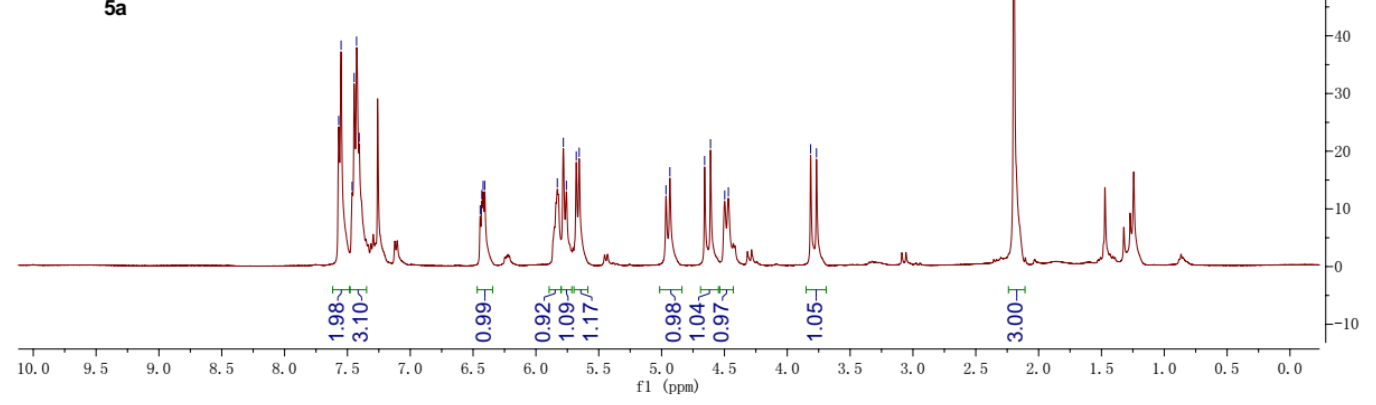



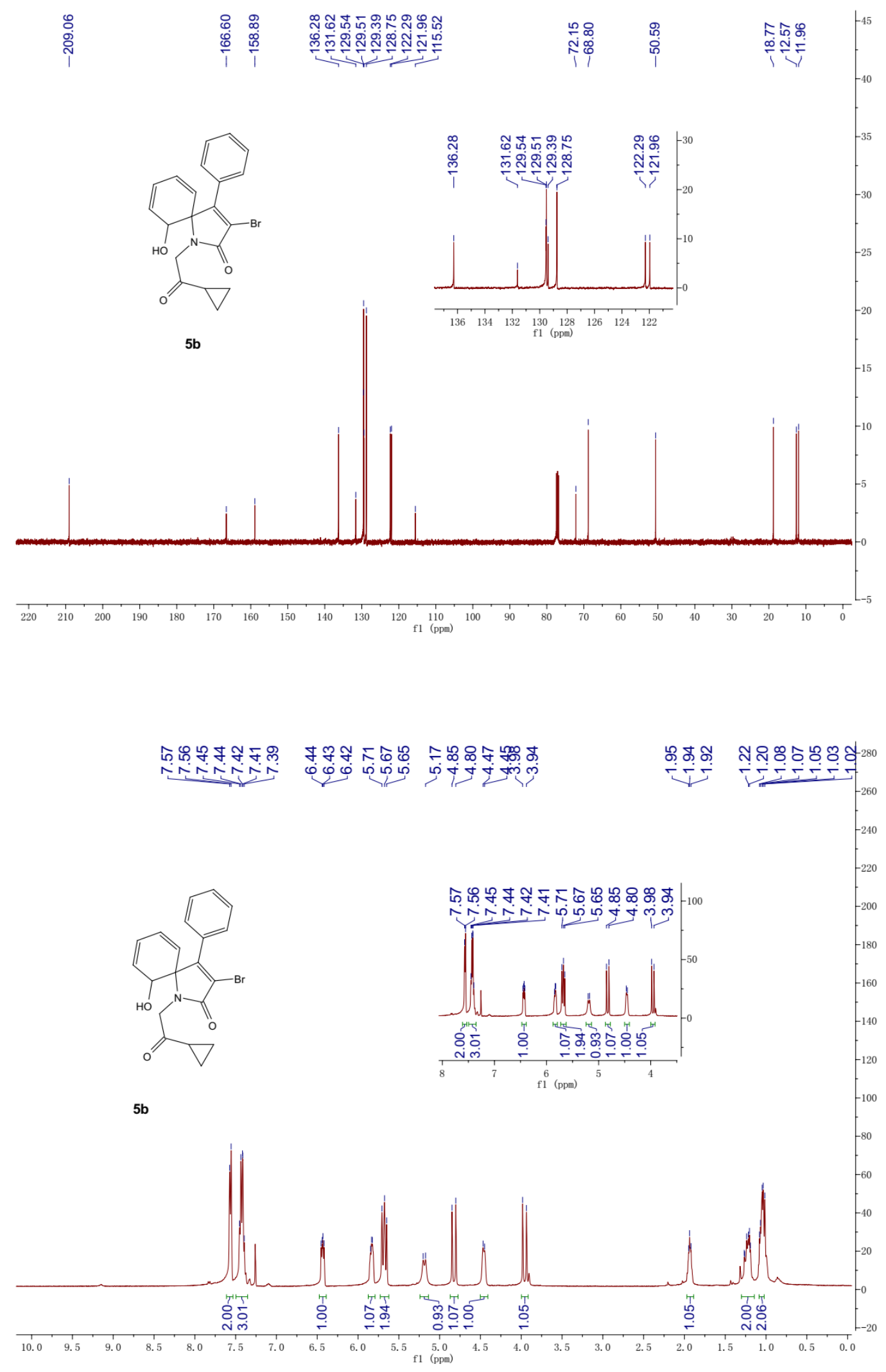

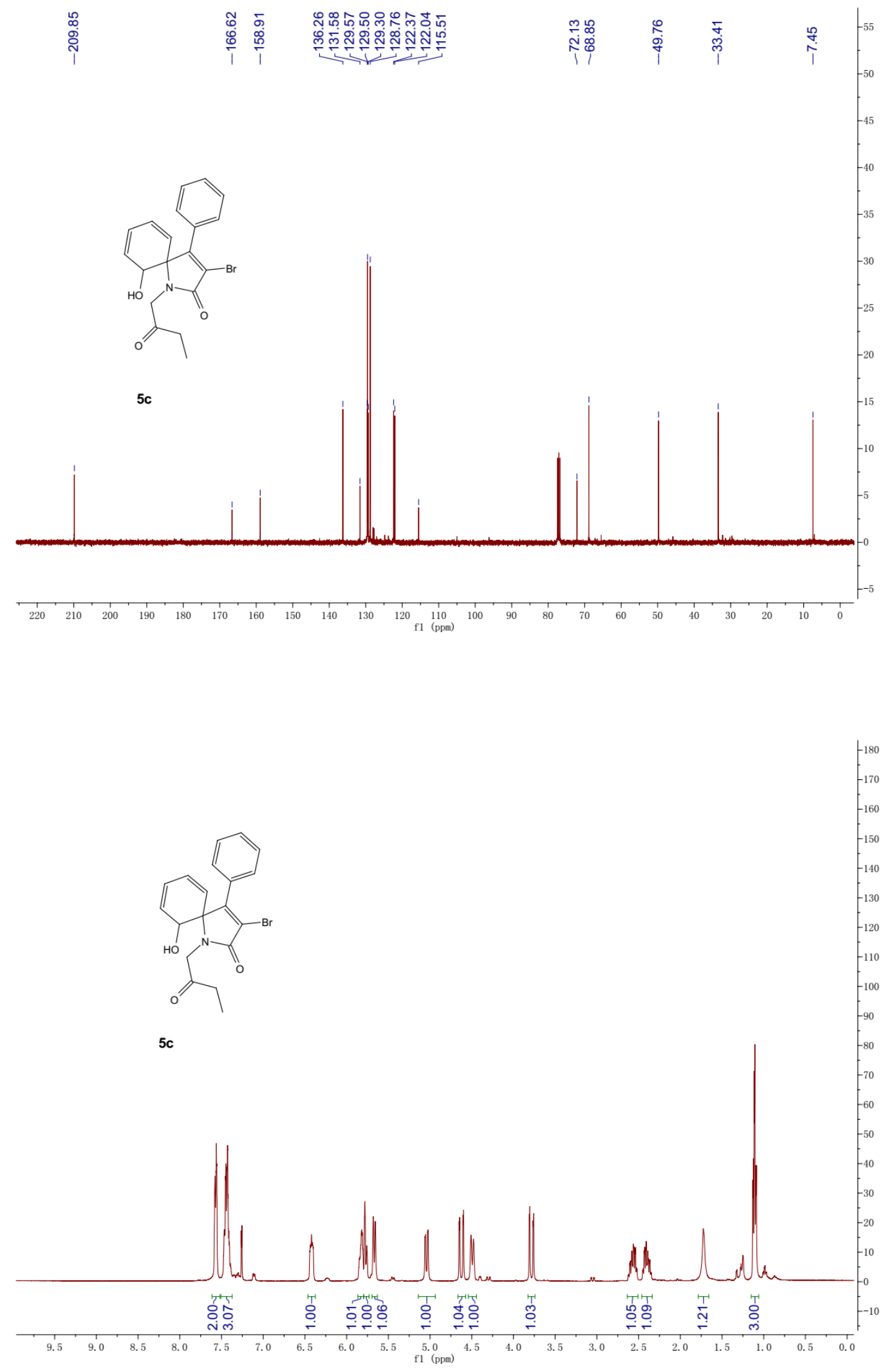

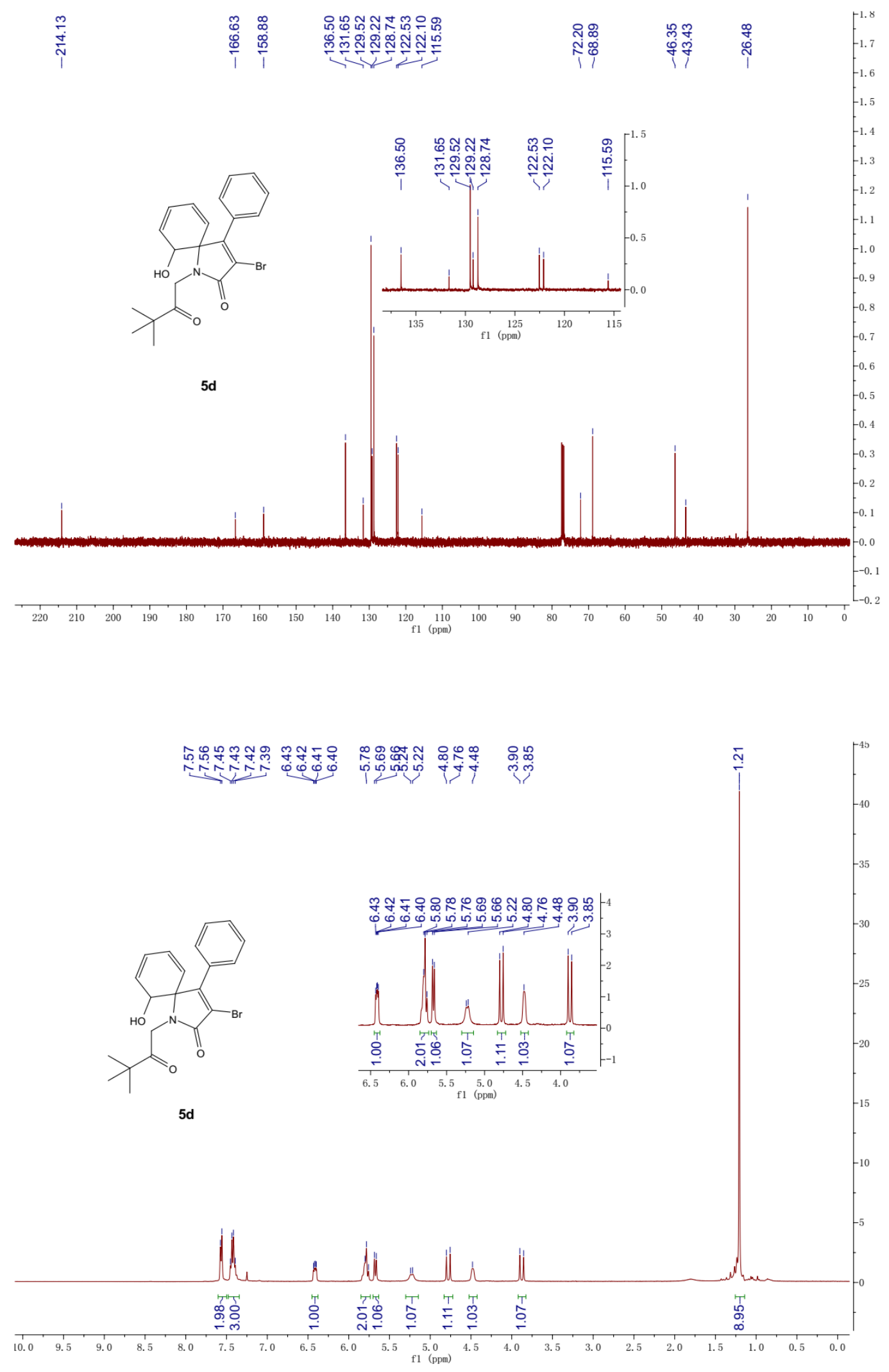

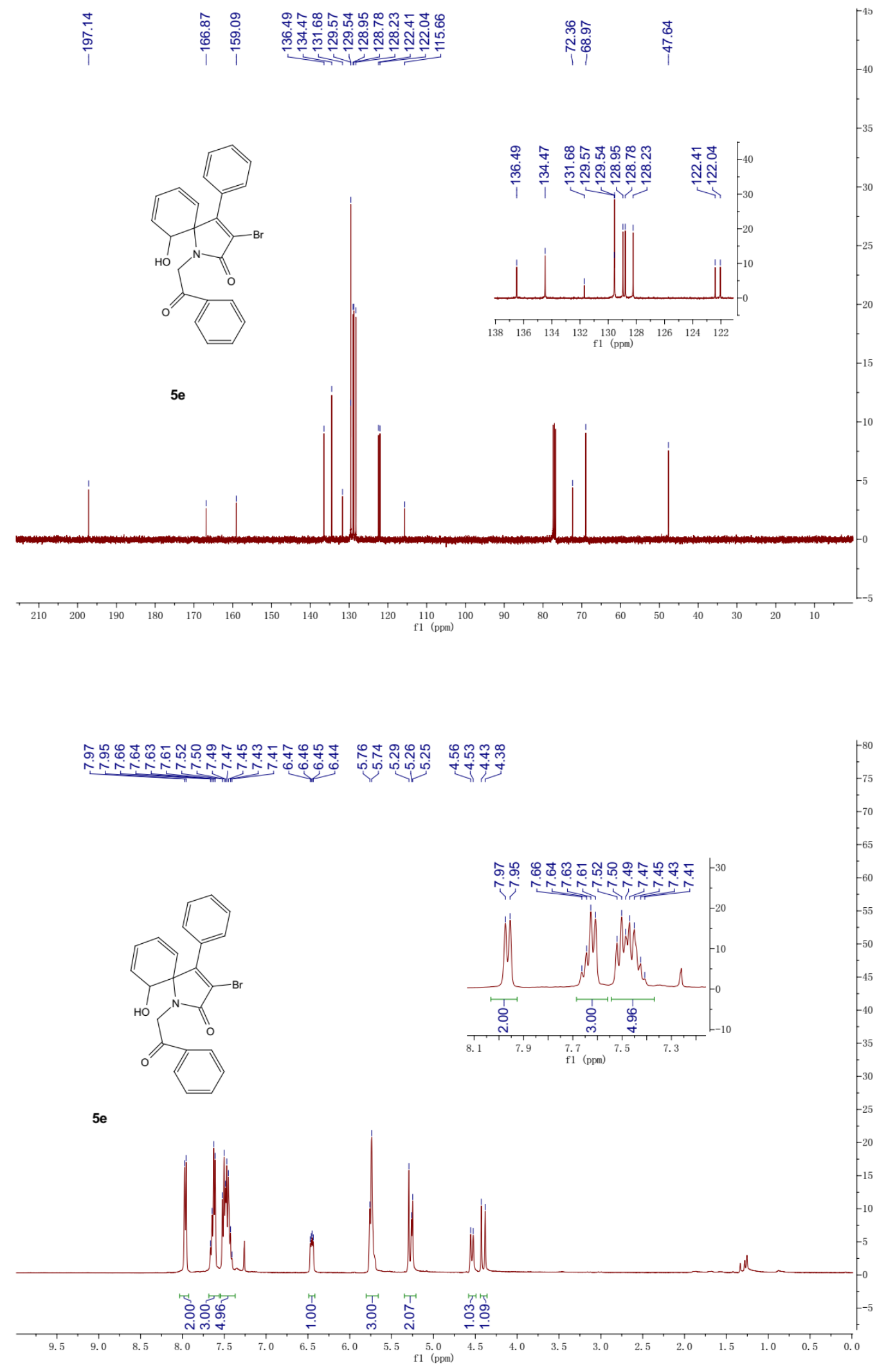


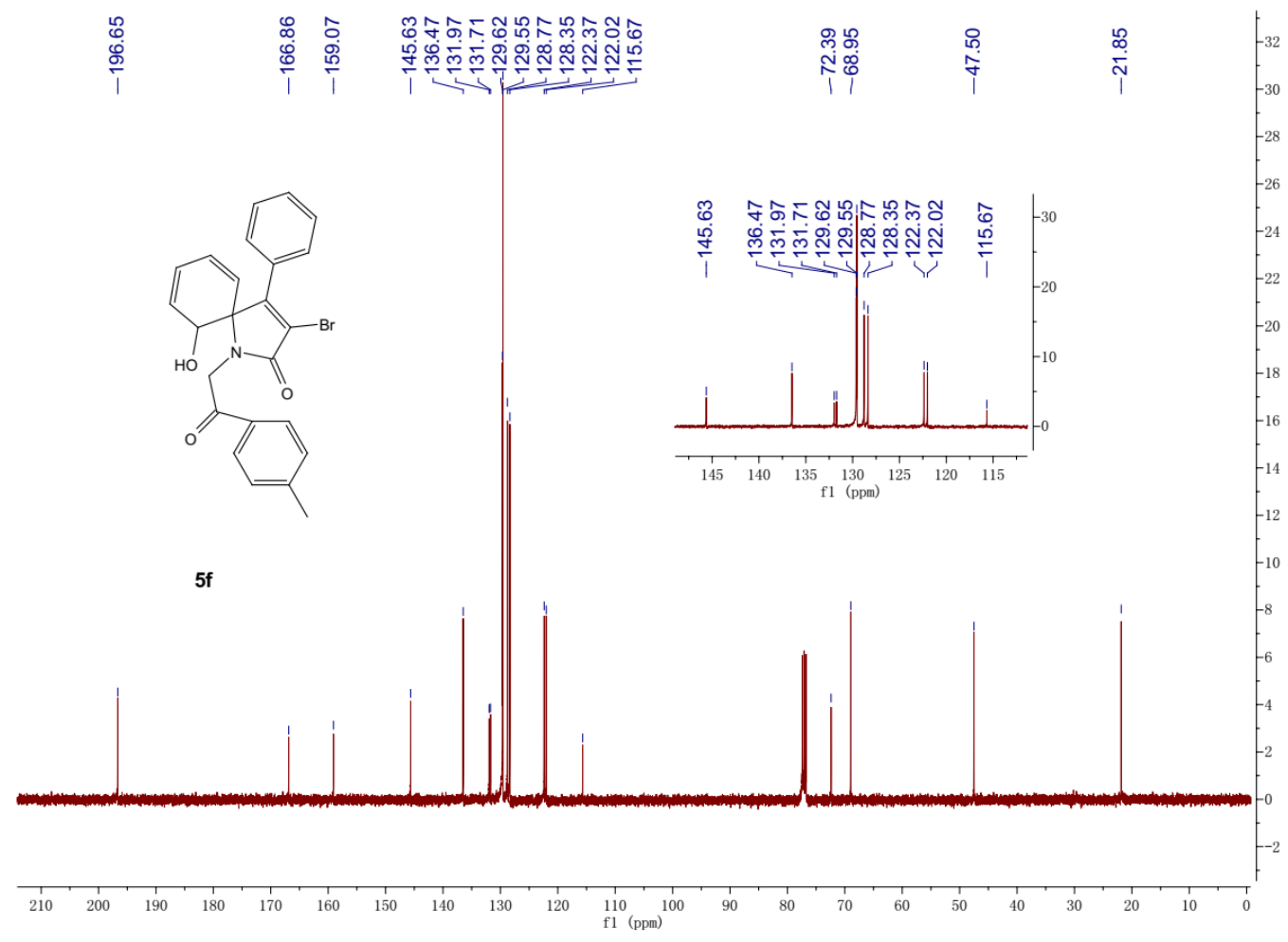

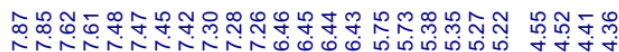

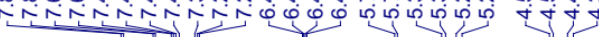
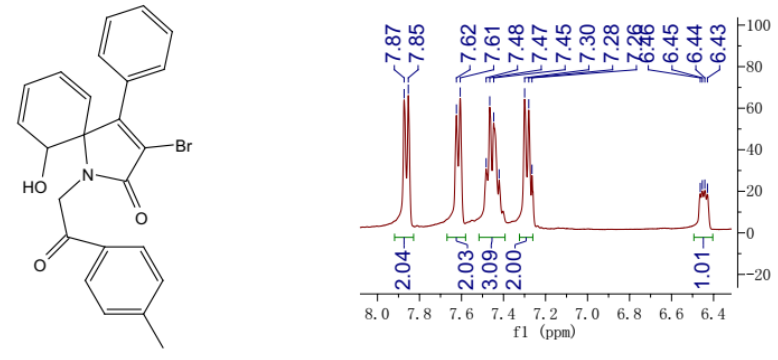

$5 f$

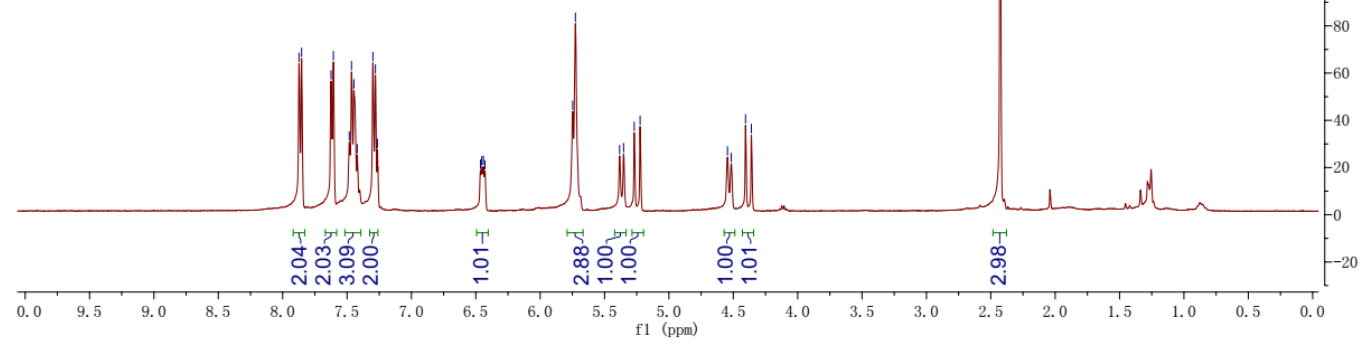



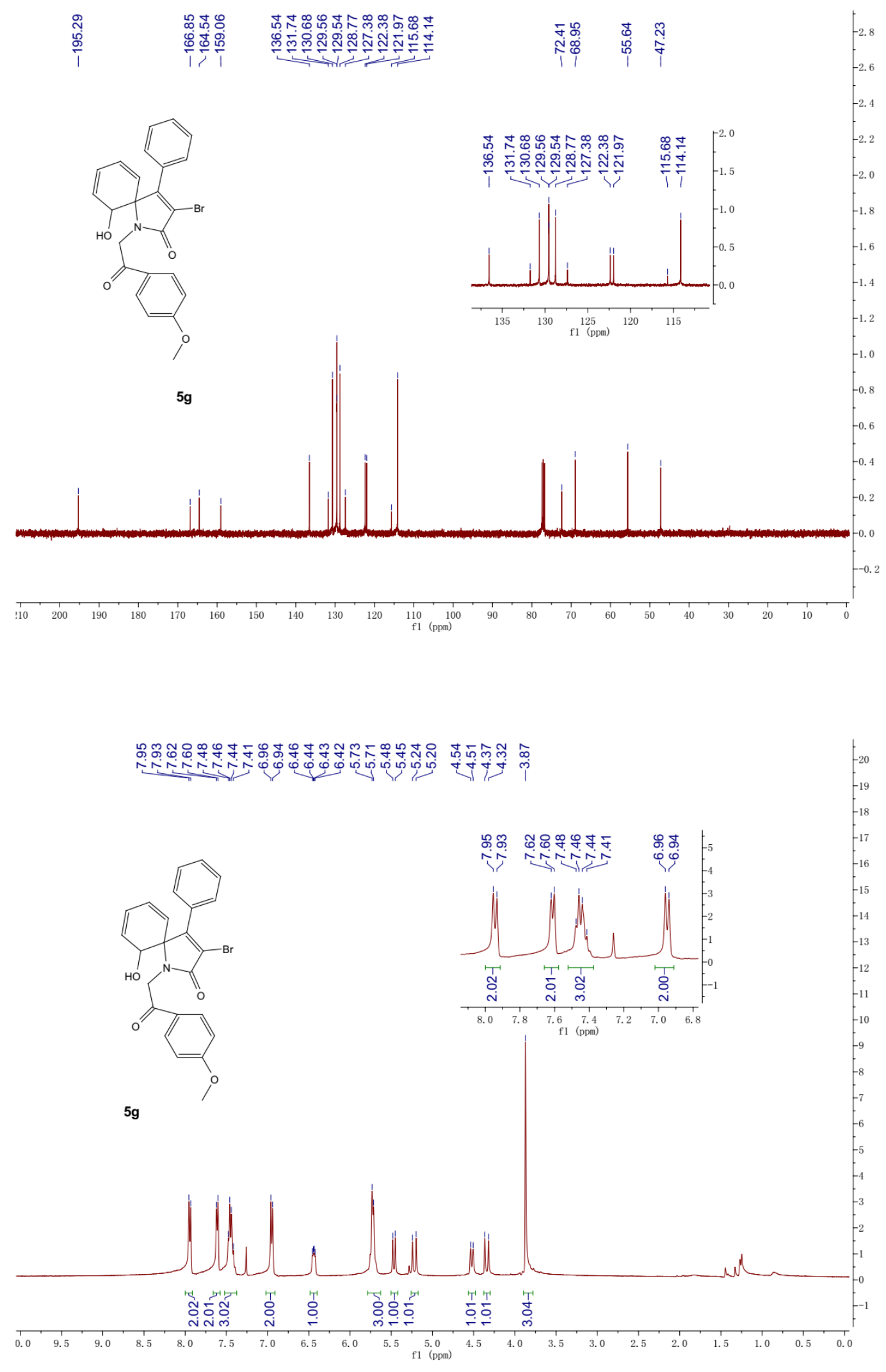

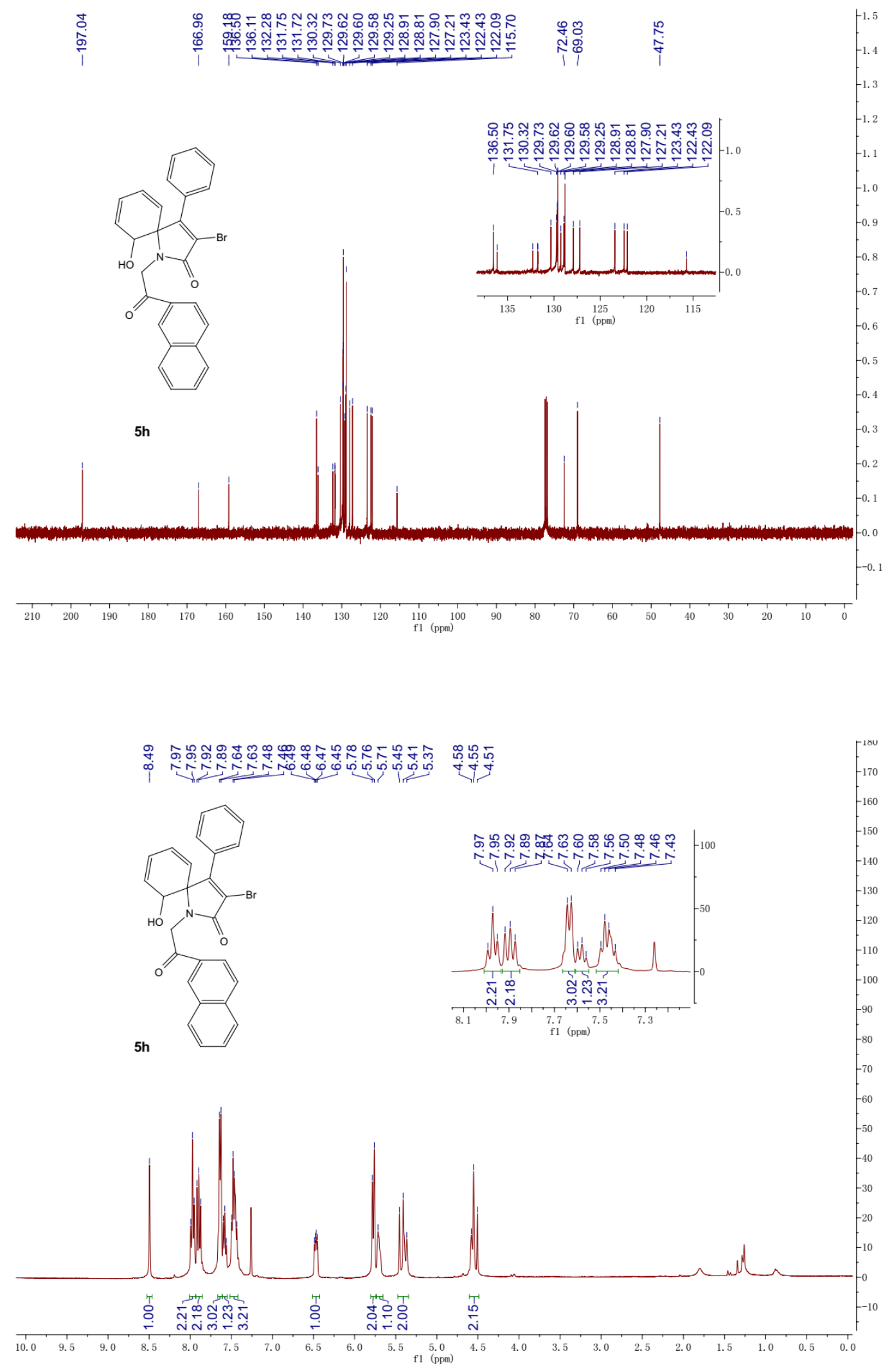

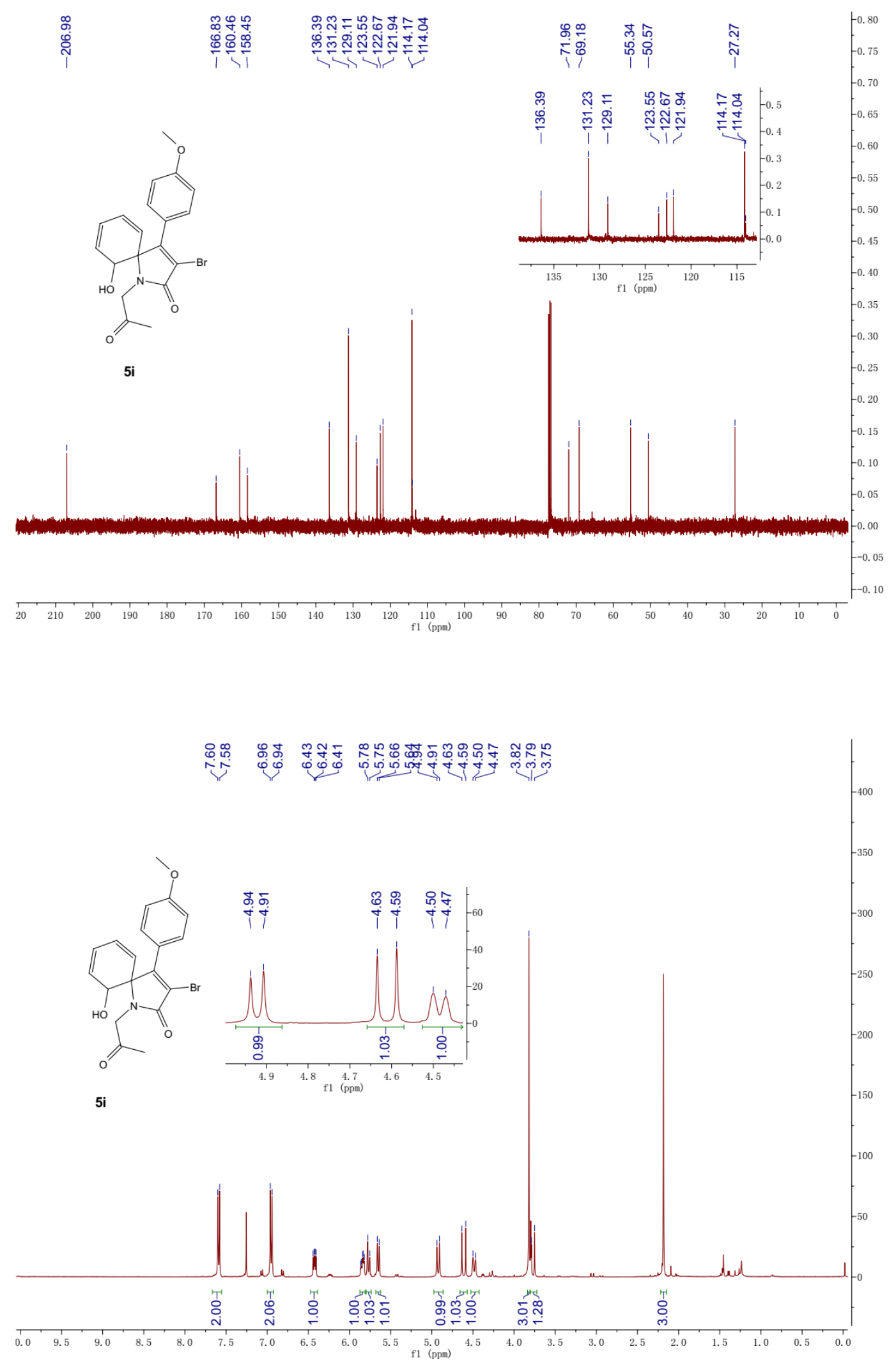

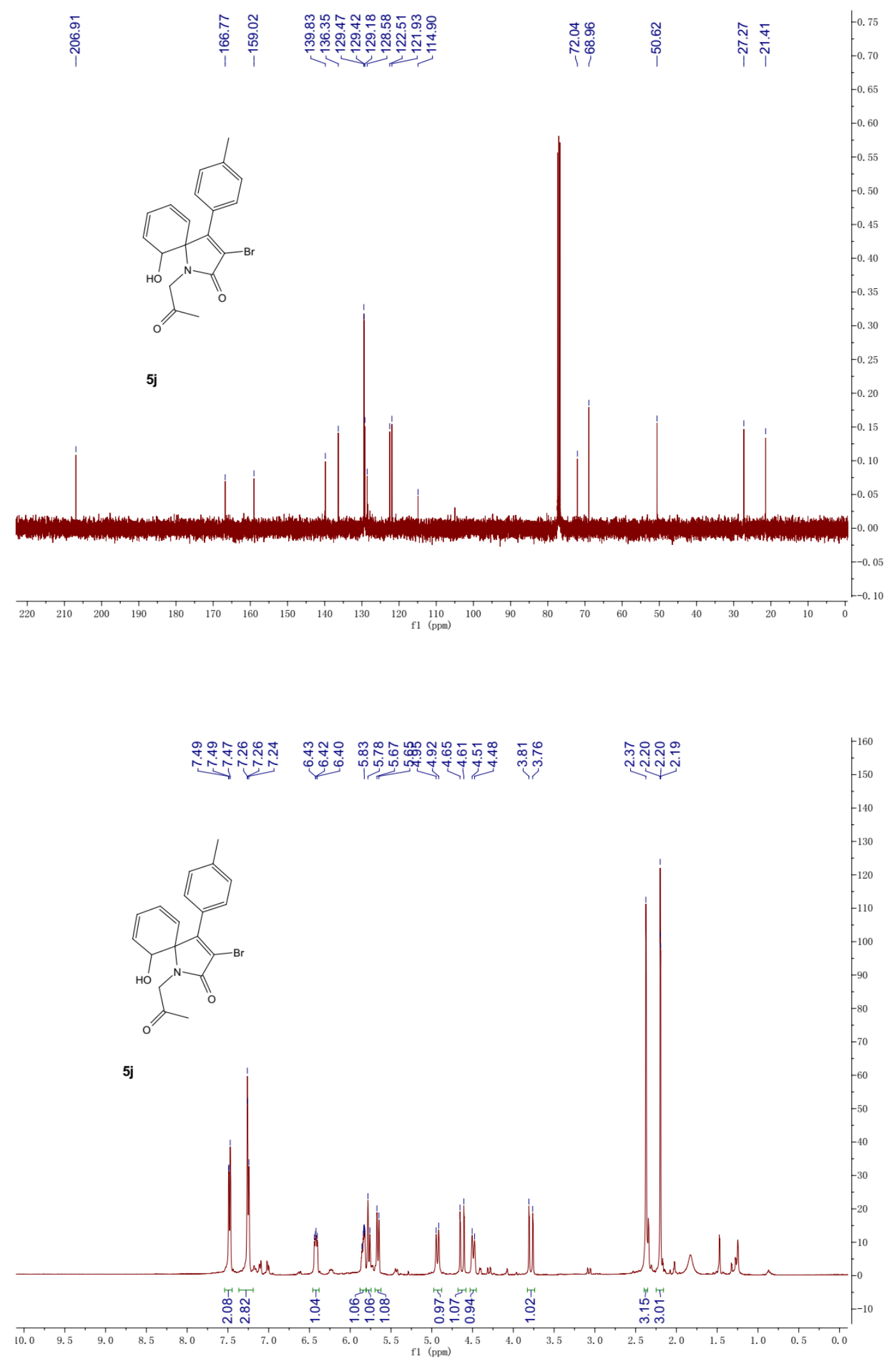


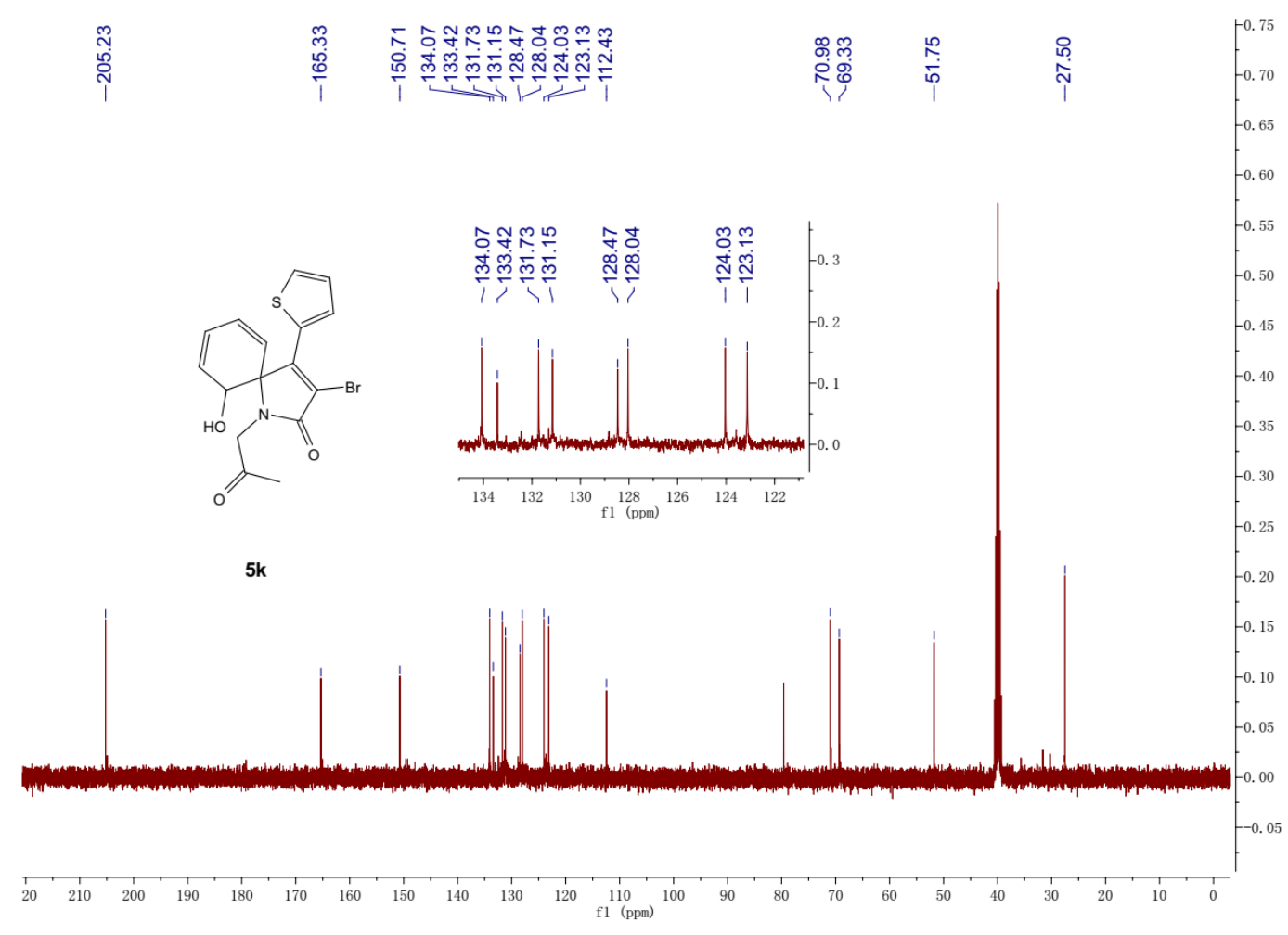

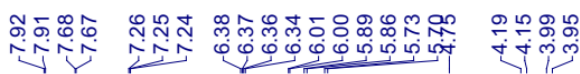
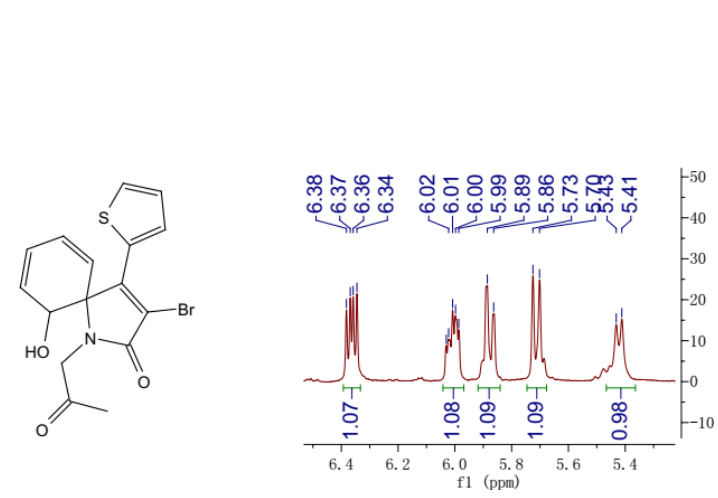

$5 k$ 


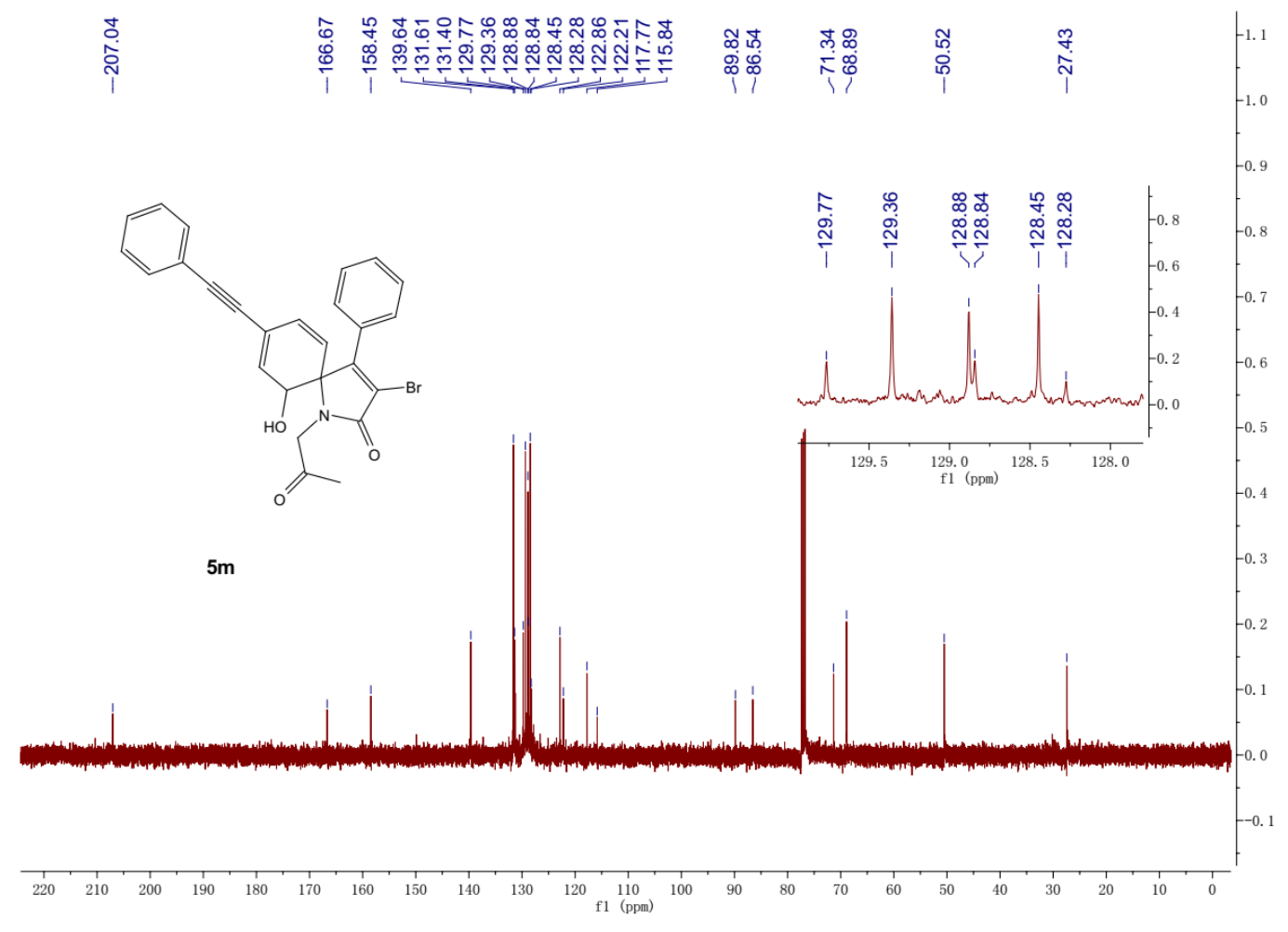

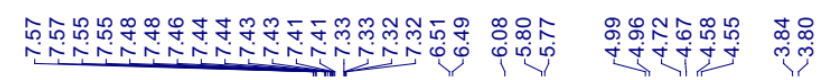

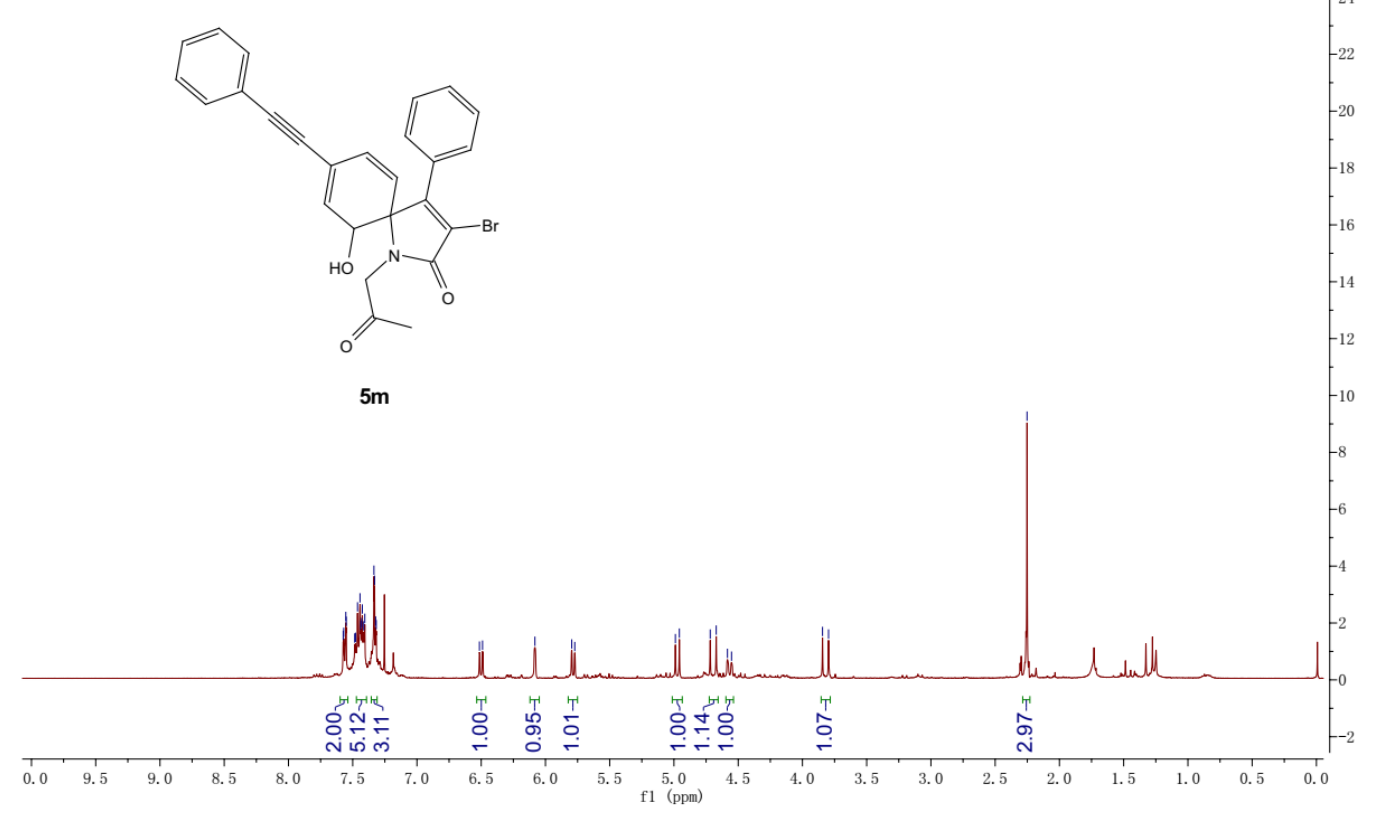



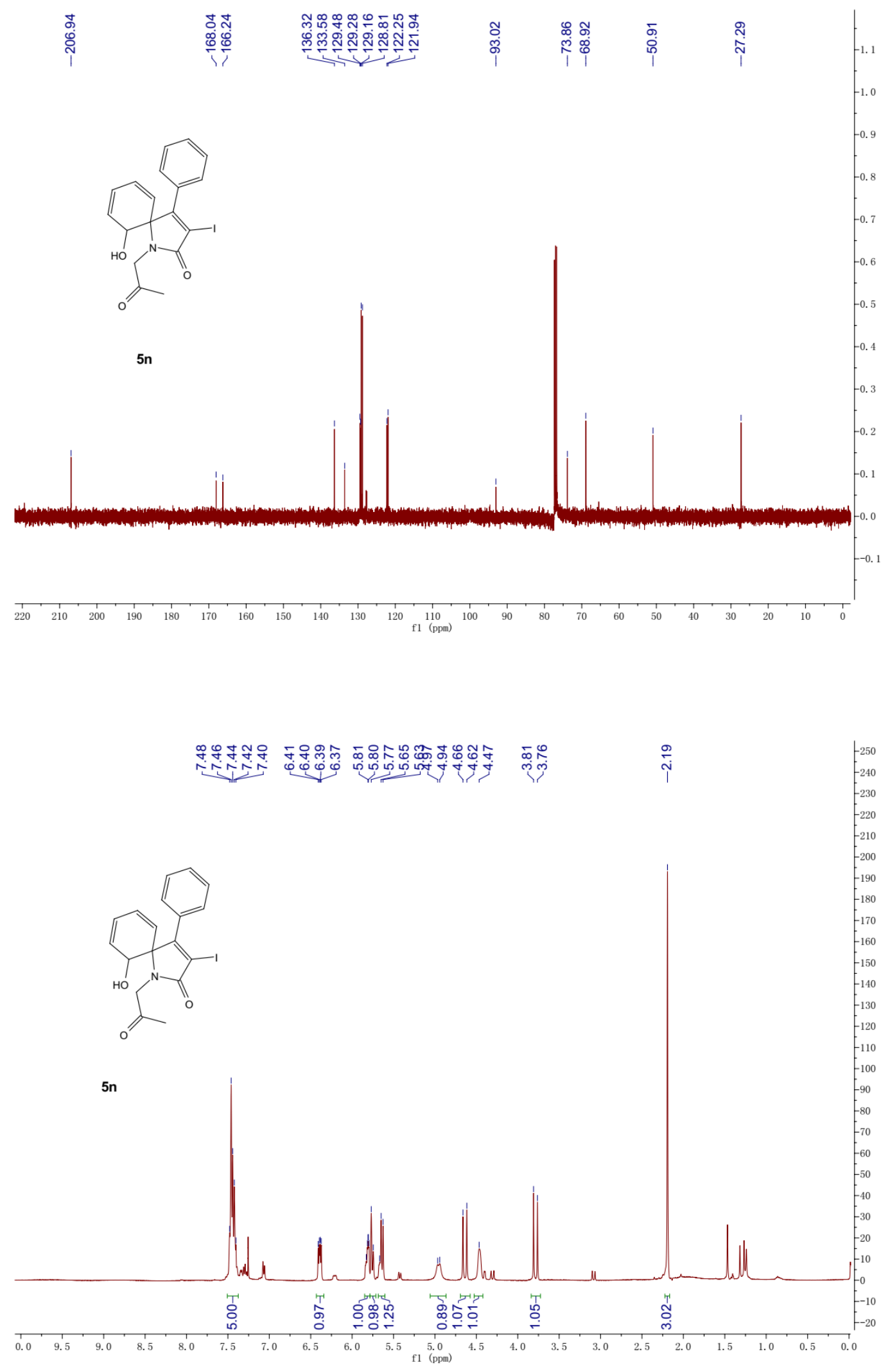


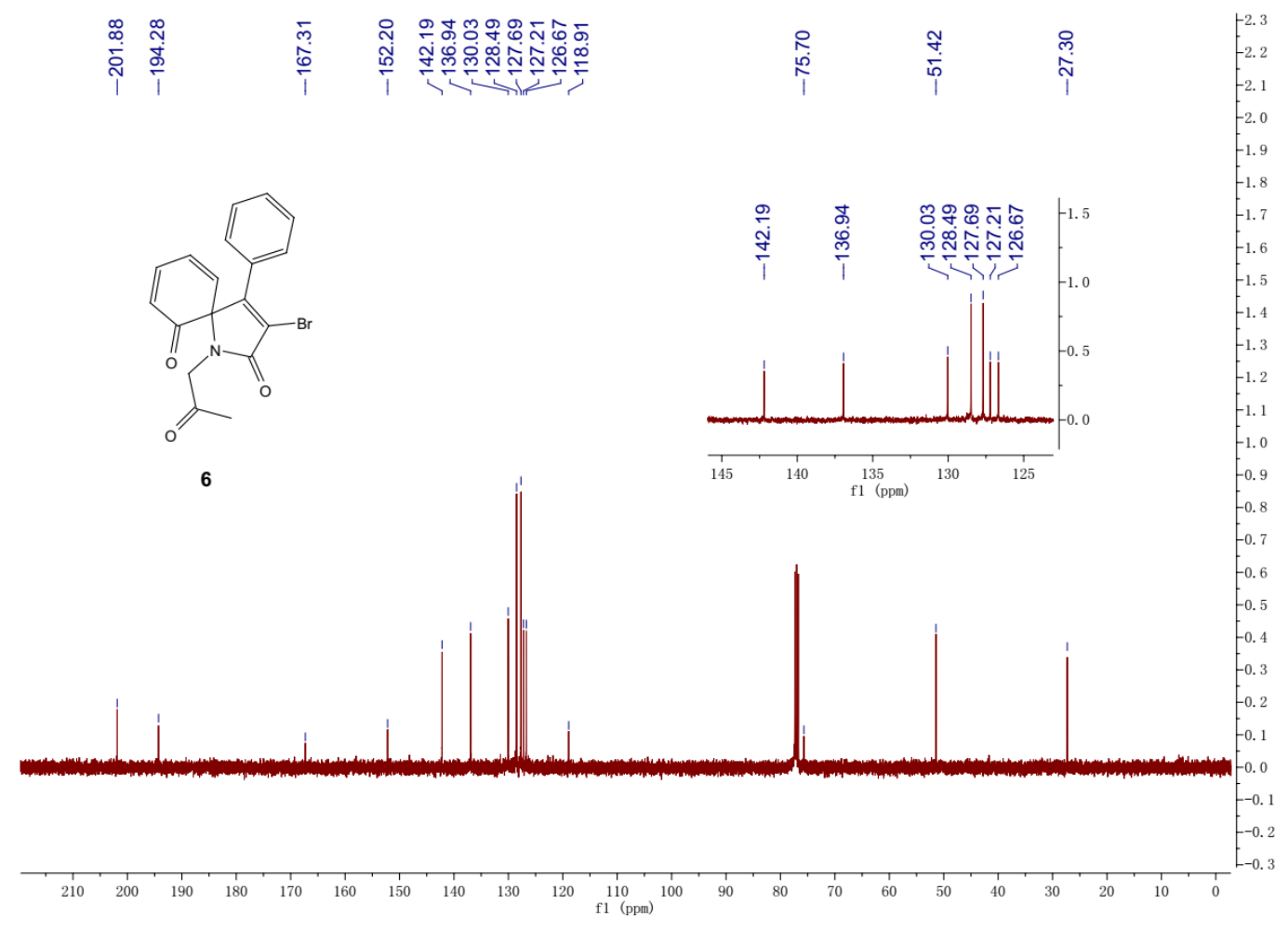

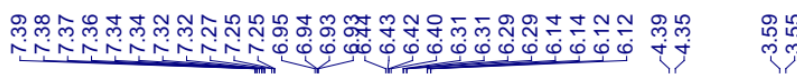
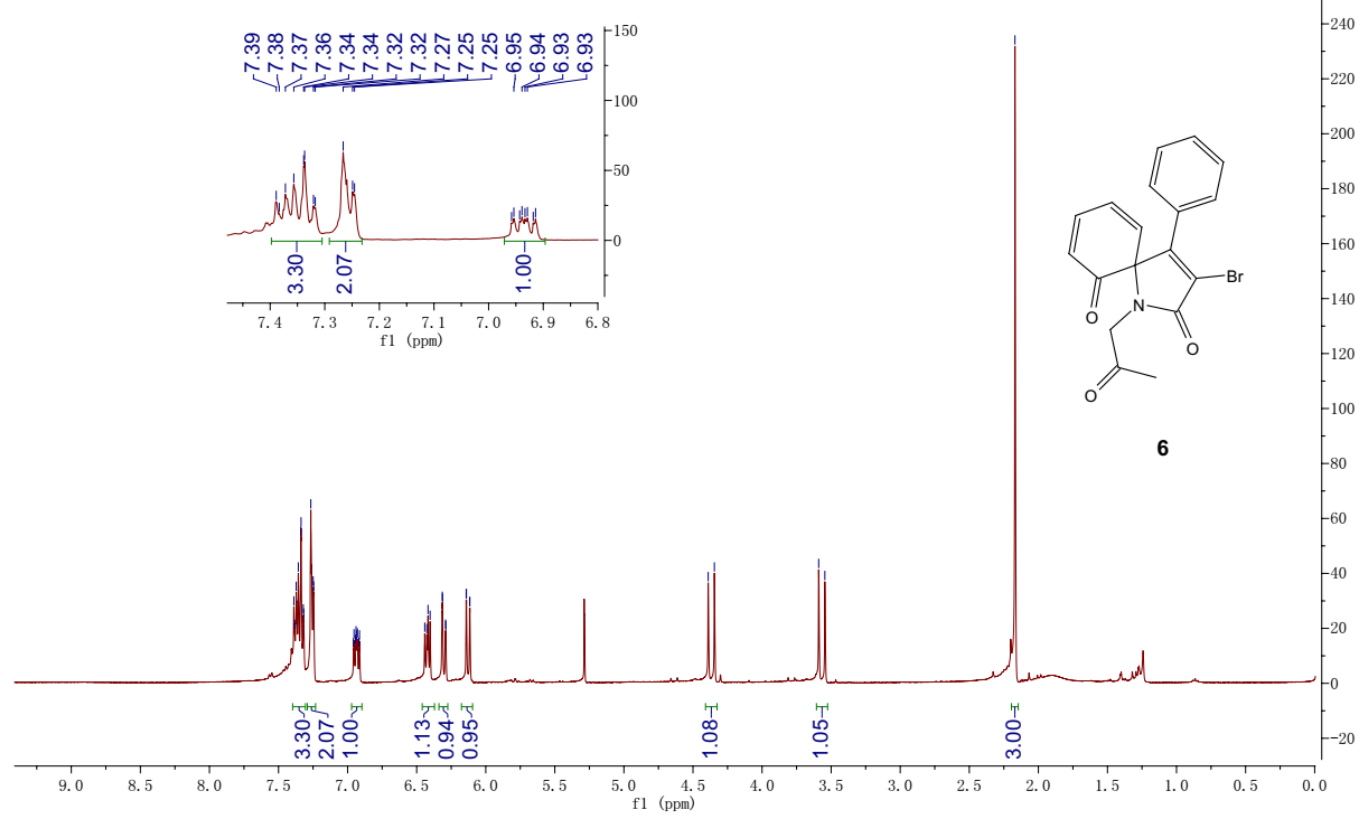

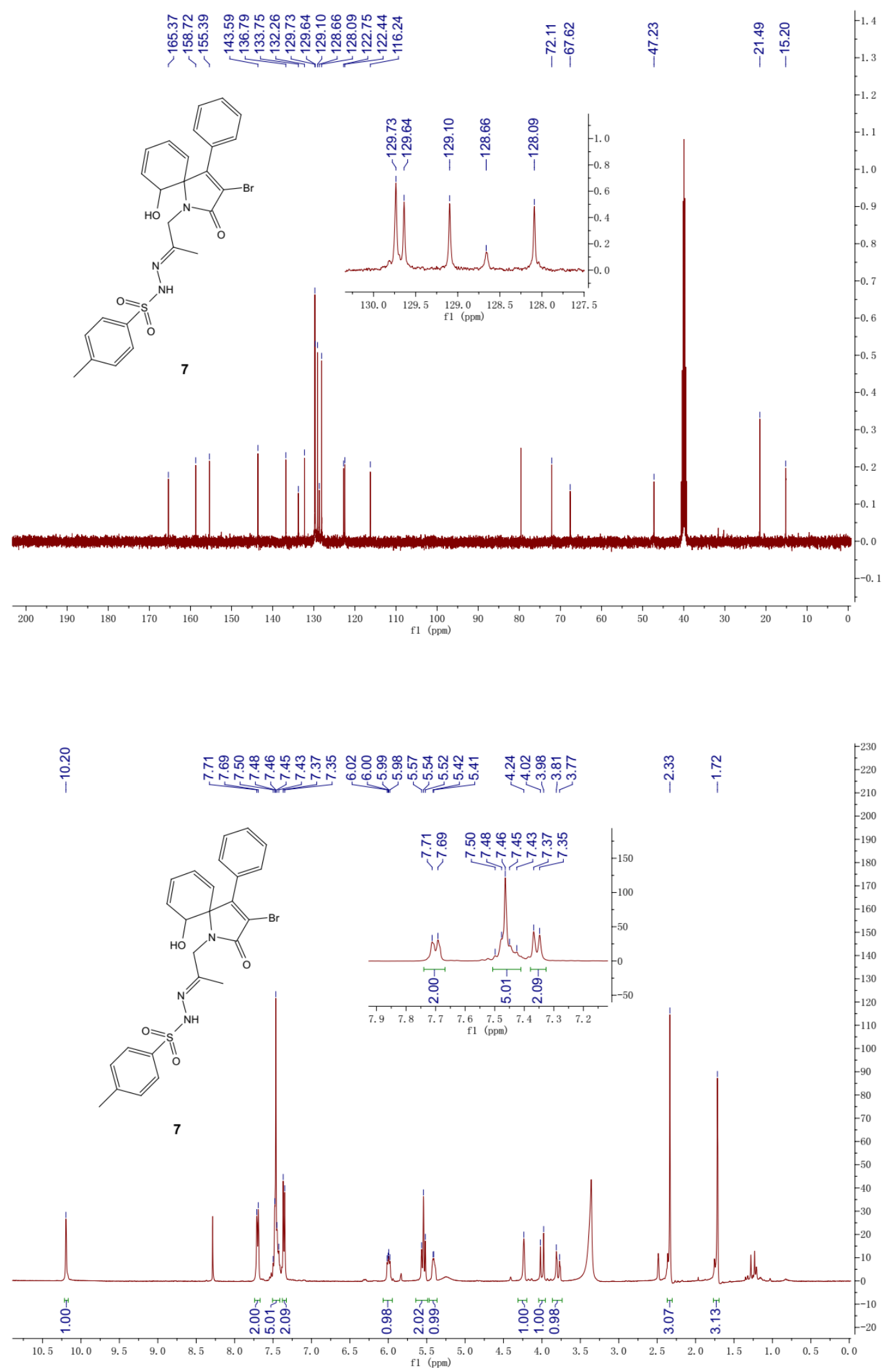